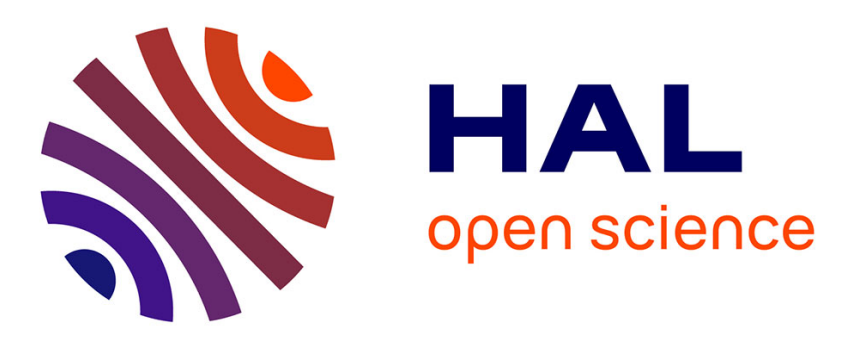

\title{
A constitutive model for cyclic actuation of high-temperature shape memory alloys
}

Yves Chemisky, Georges Chatzigeorgiou, Kumar Parikshith, Dimitris

Lagoudas

\section{- To cite this version:}

Yves Chemisky, Georges Chatzigeorgiou, Kumar Parikshith, Dimitris Lagoudas. A constitutive model for cyclic actuation of high-temperature shape memory alloys. Mechanics of Materials, 2014, 68, pp.120-136. 10.1016/j.mechmat.2013.07.020 . hal-01199736

\section{HAL Id: hal-01199736 \\ https://hal.science/hal-01199736}

Submitted on 16 Sep 2015

HAL is a multi-disciplinary open access archive for the deposit and dissemination of scientific research documents, whether they are published or not. The documents may come from teaching and research institutions in France or abroad, or from public or private research centers.
L'archive ouverte pluridisciplinaire HAL, est destinée au dépôt et à la diffusion de documents scientifiques de niveau recherche, publiés ou non, émanant des établissements d'enseignement et de recherche français ou étrangers, des laboratoires publics ou privés. 


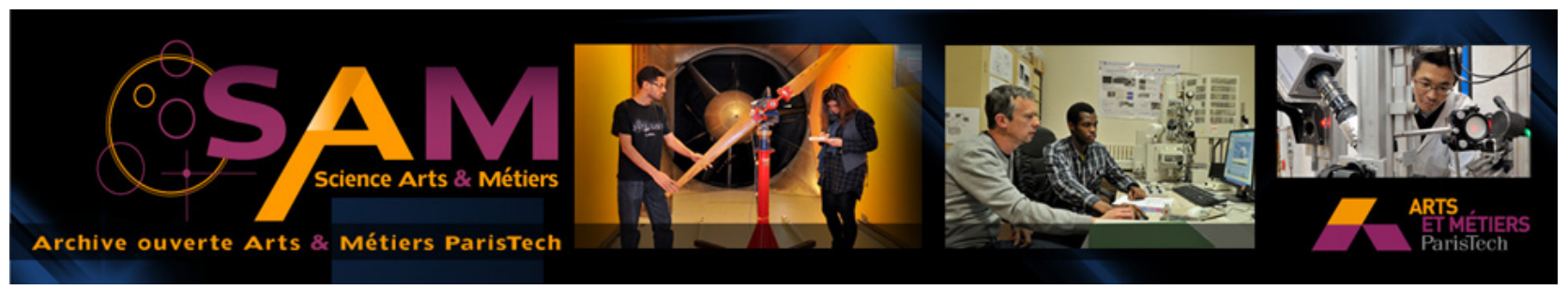

\section{Science Arts \& Métiers (SAM)}

is an open access repository that collects the work of Arts et Métiers ParisTech researchers and makes it freely available over the web where possible.

This is an author-deposited version published in: http://sam.ensam.eu

Handle ID: .http://hdl.handle.net/10985/10020

\section{To cite this version :}

Yves CHEMISKY, George CHATZIGEORGIOU, Kumar PARIKSHITH, Dimitris LAGOUDAS - A constitutive model for cyclic actuation of high-temperature shape memory alloys - Mechanics of Materials - Vol. 68, p.120-136 - 2014 


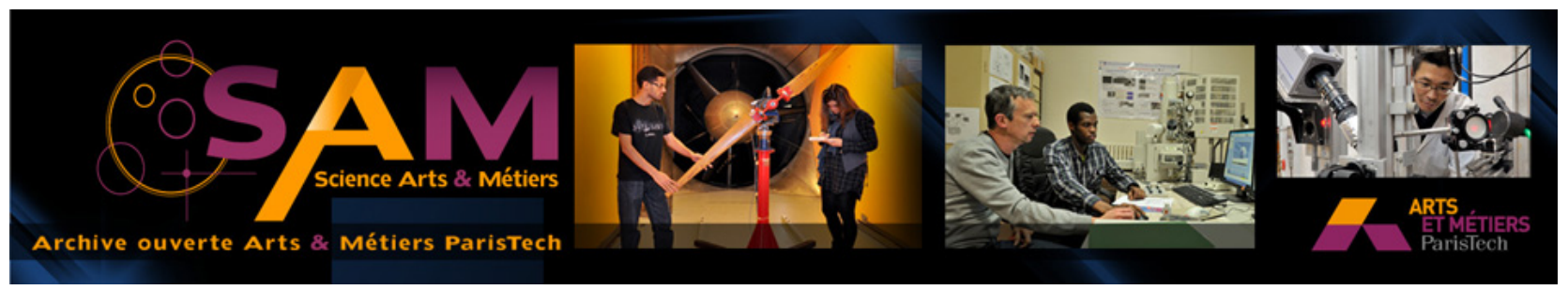

Science Arts \& Métiers (SAM)

is an open access repository that collects the work of Arts et Métiers ParisTech researchers and makes it freely available over the web where possible.

This is an author-deposited version published in: http://sam.ensam.eu Handle ID: .http://hdl.handle.net/null

\section{To cite this version :}

Yves CHEMISKY - A constitutive model for cyclic actuation of high-temperature shape memory alloys - A constitutive model for cyclic actuation of high-temperature shape memory alloys - Vol. 68, p.120-136- 2014 


\title{
A Constitutive Model for Cyclic Actuation of High-Temperature Shape Memory Alloys
}

\author{
Yves Chemisky ${ }^{\mathrm{a}}$, George Chatzigeorgiou ${ }^{\mathrm{b}}$, Parikshith Kumar ${ }^{\mathrm{c}}$, Dimitris C. Lagoudas ${ }^{\mathrm{c}, *}$ \\ ${ }^{a}$ Arts et Métiers ParisTech Metz, LEM3 UMR CNRS 7239, Metz, France \\ ${ }^{b}$ Chair of Applied Mechanics, Friedrich-Alexander Universität Erlangen-Nürnberg, Egerlandstrasse 5, \\ 91058 Erlangen, Germany \\ ${ }^{c}$ Dept. of Aerospace Engineering, Texas A $8 M$ University, 3409 TAMU College Station, TX 77843-3409, \\ $U S A$
}

\begin{abstract}
In this work, a three dimensional constitutive model for High Temperature Shape Memory Alloys (HTSMAs) is presented. To describe the evolution of the cyclic actuation behavior of such alloys, viscoplastic mechanisms and transformation induced plasticity are introduced in addition to the classical transformation behavior of Shape Memory Alloys. Based on continuum thermodynamics, the evolution of phase transformation, plasticity induced transformation, retained martensite and viscoplasticity are described. Deformation mechanisms that occur over the operational range of such HTSMAs have been identified from the thermomechanical behavior of a NiTiPd alloy. The proposed model has therefore been validated based on the prediction of the thermomechanical behavior of the studied NiTiPd HTSMA alloy under different loading conditions. Careful attention is devoted to the calibration procedure to identify the contribution of the different mechanisms independently. Finite element analysis (FEA) is performed to demonstrate the capabilities of the model to describe the cyclic behavior of HTSMA devices.
\end{abstract}

Keywords: Shape memory alloys, HTSMAs, viscoplasticity, martensitic phase transformation, cyclic actuation

${ }^{*}$ Corresponding author.

Email address: lagoudas@tamu.edu (Dimitris C. Lagoudas) 


\section{Introduction}

Shape Memory Alloys (SMAs) have been investigated for engineering applications since the later half of the $20^{\text {th }}$ century due to their ability to recover substantial deformation. Among other unique behaviors, their high recoverable strains and associated actuation work density have made them prominent for the design of actuators for the aerospace, petroleum and biomedical industries (Otsuka and Wayman, 1999; Lagoudas, 2008). Driven by industrial applications, especially aerospace and oil industries that demand actuation at high operational temperatures (DeCastro et al., 2005; Andersen and Sangesland, 1999), a new class of alloys, referred to as High Temperature Shape Memory Alloys (HTSMAs) have been developed (Wu and Wayman, 1987; Lidquist and Wayman, 1990; Pu et al., 1995; Thoma and Boehm, 1999; Kockar et al., 2006; Ma et al., 2010). These alloys can operate at temperatures higher than $100^{\circ} \mathrm{C}$, which make them an attractive alternative to legacy electrical or hydraulic actuators.

Among the different alloys that exhibit martensitic transformation above $100^{\circ} \mathrm{C}, \mathrm{NiTiPd}$ HTSMAs have been investigated for their actuation capabilities at temperatures ranging from $200-500^{\circ} \mathrm{C}$ and stress levels greater than $100 \mathrm{MPa}$ (Lidquist and Wayman, 1990; Lindquist, 1988; Golberg et al., 1994, 1995b,a; Lindquist, 1988; Noebe et al., 2006; Padula II et al., 2006; Cai et al., 2000). At these operational conditions, constant stress thermal cycles lead to the appearance of irrecoverable rate independent and rate dependent strains, which affect the actuation performance. As a consequence, these materials are suitable for applications that requires limited actuation cycles. To develop a design tool adapted to HTSMA actuators, a constitutive model that considers the effects related to the phase transformation and viscoplasticity is necessary to predict the evolution of irrecoverable strains during cyclic actuation. This paper is focused on the development of such a constitutive model for HTSMAs based on a thermodynamic framework. Particular attention is devoted to the prediction of actuation capability and the appearance of irrecoverable strains during cyclic loading.

During the last thirty years significant efforts have been conducted on developing constitutive models for regular SMAs (Tanaka et al., 1986; Liang and Rogers, 1990; Brinson, 1993; Boyd and Lagoudas, 1996; Leclercq and Lexcellent, 1996; Savi et al., 2002). These models were incrementally improved over the last ten years and implemented in Finite Element 
Analysis (FEA) packages (Qidwai and Lagoudas, 2000; Panico and Brinson, 2007; Lagoudas et al., 2012; Chemisky et al., 2011; Sedlak et al., 2012). All these models describe the behavior of conventional SMAs and, since the operating temperatures and maximum stress levels are relatively low, no influence of irrecoverable strains due to creep or high stress effects have been taken into account. The evolution of transformation induced plasticity has been further considered for conventional SMAs by Bo and Lagoudas (1999b) and Lagoudas and Entchev (2004b) to account for the appearance of irrecoverable strains upon cycling. The coupling between phase transformation and plasticity has been considered in the literature for the simulation of shape memory alloys that operates a low temperatures (compared to their melting temperatures), but where the stress level can reach the plastic yield stress (Hartl and Lagoudas, 2009; Zaki et al., 2010; Khalil et al., 2012). A one dimensional model accounting for the coupling between phase transformation and viscoplasticity has been recently developed by Lagoudas et al. (2009) for the simulation of HTSMAs, where viscoplastic creep is observed. A three-dimensional extension of this model was developed and implemented in a FEA software by Hartl et al. (2010b). The model focused on the unique behavior exhibited when phase transformation and viscoplasticity are occurring simultaneously, however the cyclic evolution of this behavior was not considered. The proposed model thus focuses on the appearance of irrecoverable transformation-induced rate-independent plasticity (TRIP), the accumulation of retained martensitic phase and viscoplastic strains for multiple cycle thermomechanical loading.

The determination of the deformation mechanisms that occur over the operational range of stress level and temperature has been carried out via the experimental characterization of a $T i_{50.5} P d_{30} N i_{19.5}$ HTSMA, conducted for different loading conditions (loading path, loading rate, temperature) (Kumar et al., 2011). Additional tests have been conducted and presented in this paper, to properly isolate and identify specific mechanisms such as the evolution of retained martensite and plasticity during transformation. Also, creep test have been conducted to properly identify the viscoplastic behavior of the alloy.

Based on the experimental observation of deformation mechanisms, a thermodynamical constitutive model is proposed, with several unique features: i) an adapted law for the evolution of transformation-induced plasticity; ii) the description of the evolution of 
retained martensite and iii) the description of simultaneous transformation/viscoplastic behavior based on a viscoplastic law accounting for cyclic evolution of primary and secondary creep. The implementation of a viscoplastic power law including hardening effects (Lemaitre and Chaboche, 2002) allows for the simulation of such behavior. The introduction of a volume fraction of retained martensite is motivated by the experimental evidence of the presence of a martensitic phase in NiTiPd systems at high temperature above $A_{f}\left(A_{f}+100^{\circ} \mathrm{C}\right)(\mathrm{Ku}-$ mar and Lagoudas, 2010). It has been observed that retained martensite is pinned by the accumulation of plastic strains generated during transformation.

The calibration of the proposed model is based on the experimental characterization of the $T i_{50.5} P d_{30} N i_{19.5}$ HTSMA. The viscoplastic behavior is calibrated from creep and uniaxial tests conducted at different stress-temperature conditions. The model parameters related to rate-independent mechanisms are calibrated based on constant stress thermal cycles. To validate the model, the prediction of the actuation response of HTSMAs under different conditions are compared with additional cyclic actuation tests.

The work is organized as follows: Section 2 describes some of the earlier tests along with additional thermomechanical characterization of the investigated NiTiPd HTSMA, with uniaxial isothermal compression tests, isobaric thermal actuation cycles at different heating/cooling rates with and without creep. The unique response of this HTSMA is analyzed in this section to motivate the definition of a 3-D constitutive model, based on continuum thermodynamics, presented in section 3. Section 4.1 presents the calibration procedure of the proposed model. The final section presents the comparison of the model with a set of experiments performed on a $N i T i P d_{30}$ HTSMA, from the calibration experiments to a designated set of validation experiments, to discuss the prediction capabilities of the model. Finally, numerical examples are presented, that include the thermomechanical response of complex structures undergoing multiple actuation cycles. The conclusions of this work are summarized in the last section.

\section{Material Selection and Experimental Characterization}

From an array of NiTiX (X=Pd, Pt, Hf, Zr or Au) HTSMAs available presently, NiTiPd based systems have shown good actuation characteristics at operational temperatures higher 
than NiTiHf or NiTiZr based systems (Lidquist and Wayman, 1990; Lindquist, 1988; Golberg et al., 1994, 1995b,a). For the present work, the $T i_{50.5} P d_{30} N i_{19.5}$ composition is chosen because this particular composition has been widely investigated in the literature (Noebe et al., 2006; Padula II et al., 2006; Cai et al., 2000). The transformation temperatures for this composition lies between $200^{\circ} \mathrm{C}$ and $300^{\circ} \mathrm{C}(0.3-0.35$ of the absolute melting temperature), which is at the lower end of the creep regime (typically 0.3-0.5 of the absolute melting temperature) and the transformation strain is around 3.0\% (Golberg et al., 1994, 1995b,a). However, with the application of a load, it is necessary to heat the SMA to temperatures higher than the no-load transformation temperatures to ensure full actuation. Under such operating conditions both creep and the phase transformation can occur simultaneously and thus impact actuator performance (Kumar and Lagoudas, 2010; Lagoudas et al., 2009).

A hot worked $T i_{50.5} P d_{30} N i_{19.5}$ HTSMA bar was fabricated from which cylindrical specimens (7 mm diameter and $14 \mathrm{~mm}$ height) were machined for uniaxial thermomechanical tests. A custom high temperature thermomechanical test setup was utilized for the testing of the HTSMA specimens. The force, strain, temperature and time were monitored throughout the duration of the test. Further details of the alloy fabrication, specimen machining and thermomechanical tests setup are described in Kumar et al. (2011). To determine the transformation temperatures of the alloy, a preliminary thermal cycle was conducted at $10^{\circ} \mathrm{C} / \mathrm{min}$ on a specimen under a no-load condition. The transformation temperatures were determined by the tangent intersection method and test temperatures for the uniaxial, creep and the load-bias thermal cycling tests were determined from those results.

To determine the parameters that would assist with the development of the combined phase transformation, plasticity and visco-plastic model, the experiments conducted were organized in three groups to study the thermoelastic behavior, the visco-plastic behavior and the phase transformation behavior, respectively. The tests for the thermoelastic behavior and the creep experiments for the viscoplastic behavior are described in elaborate detail in Kumar et al. (2011) and therefore will not be discussed in this work. The additional tests for the viscoplastic behavior as well as the phase transformation are described in this section and their results will be presented and discussed. 


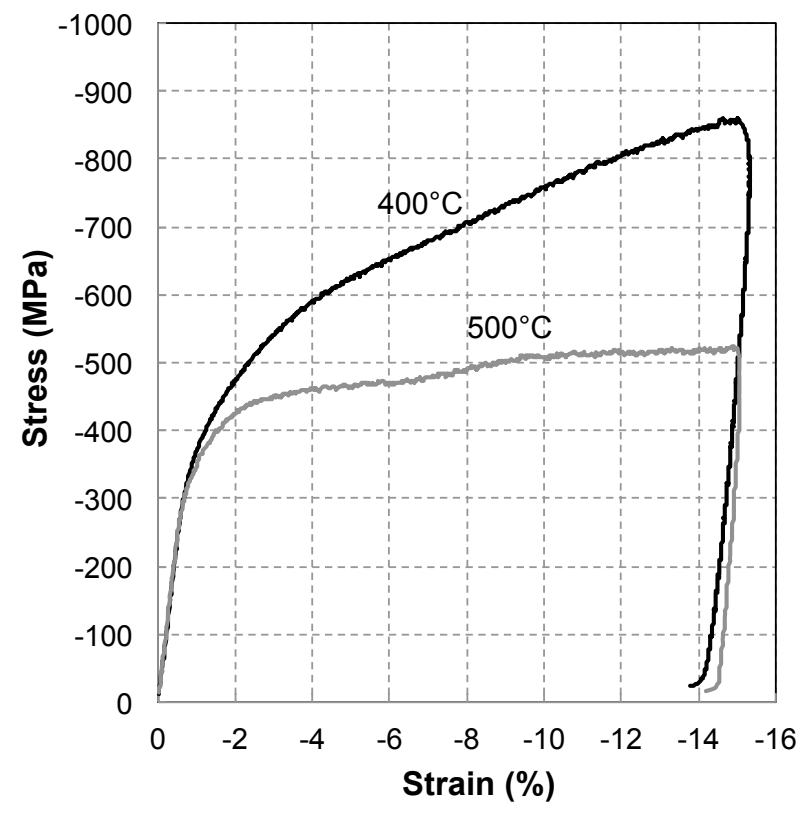

Figure 1: Uniaxial tests conducted at 400 and $500^{\circ} \mathrm{C}$ at a loading rate of $10^{-4} / \mathrm{sec}$.

\subsection{Creep Tests}

To study the viscoplastic material behavior, standard creep tests were conducted at stress levels of 100,300 , and $500 \mathrm{MPa}$ and at temperatures of $300^{\circ} \mathrm{C}, 400^{\circ} \mathrm{C}$, and $500^{\circ} \mathrm{C}$ to cover the entire operational range of the considered HTSMA. The results from these tests are described in Kumar et al. (2011). To understand the viscoplastic hardening behavior of the HTSMA, in addition to the creep tests two additional uniaxial tests were conducted at $400^{\circ} \mathrm{C}$ and $500^{\circ} \mathrm{C}$ at a loading strain rate of $10^{-4} / \mathrm{sec}$. The results from the uniaxial tests at both $400^{\circ} \mathrm{C}$ and $500^{\circ} \mathrm{C}$ are shown in Fig. 1. From the uniaxial results it is observed that the hardening behavior in the specimen decreases with increasing test temperature. This softening, and the drop in the yield stress level with the increase in the test temperature from $400^{\circ} \mathrm{C}$ to $500^{\circ} \mathrm{C}$ suggests that the plastic and viscoplastic deformations are dominant. Due to the constant strain rate of loading, the uniaxial tests provide calibration data for transient primary and secondary creep. 


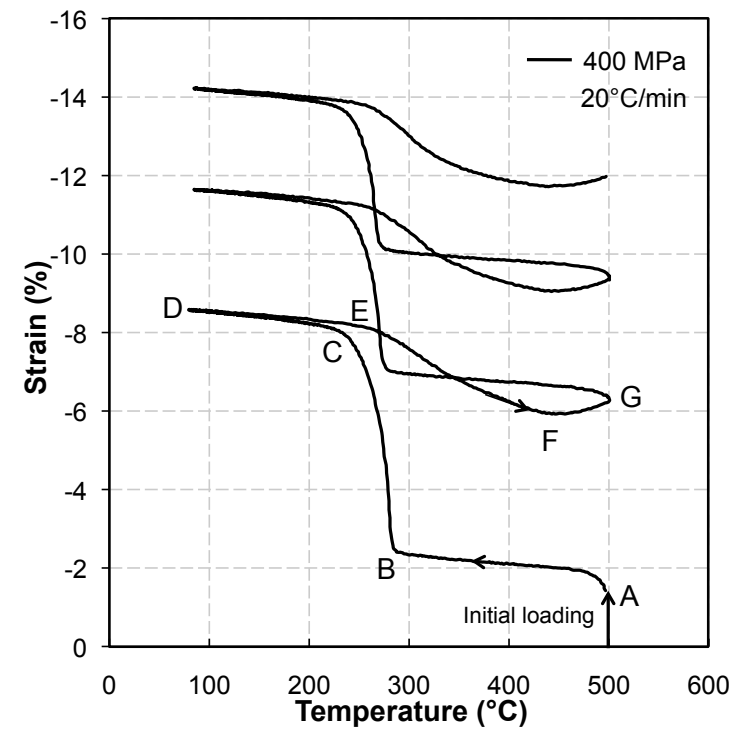

(a)

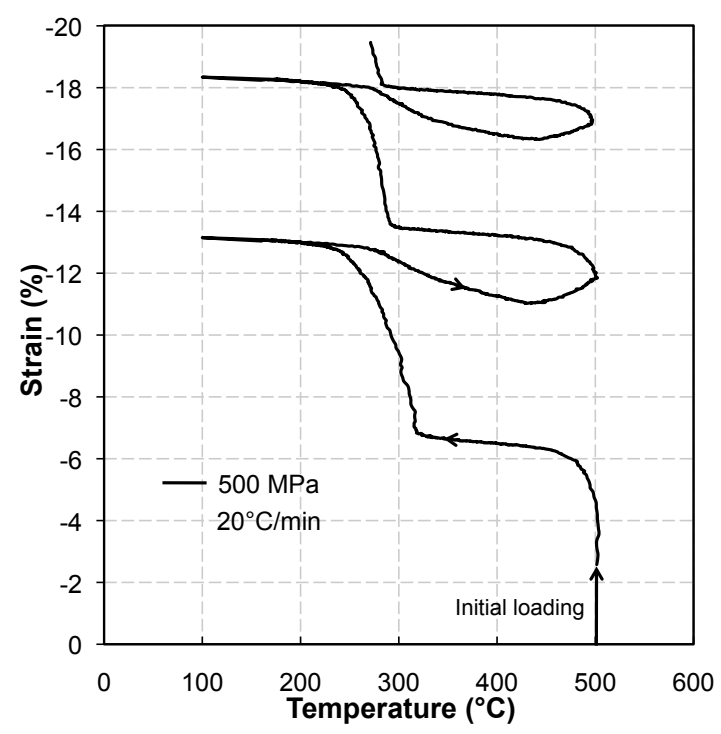

(b)

Figure 2: Load-bias thermal cycling tests at $20^{\circ} \mathrm{C} / \mathrm{min}$ conducted at a stress of (a) $400 \mathrm{MPa}$ and; (b) 500 $\mathrm{MPa}$. Simultaneous creep and phase transformation occurs during the reverse phase transformation.

\subsection{Load-Biased Thermal Cycling Tests}

To determine the transformation regions for the stress-temperature phase diagram as well as to understand the evolution of the simultaneous creep and transformation behavior, constant stress thermal cycling tests (referred to as load-bias tests) were conducted at applied compressive stress levels of 400 and $500 \mathrm{MPa}$. The upper and lower limits for the thermal cycling were fixed at $100^{\circ} \mathrm{C}$ and $500^{\circ} \mathrm{C}$, to ensure complete transformation at the highest stress level (500 MPa) and to have a consistent thermomechanical history across all thermally cycled specimens. Each specimen was heated to $500^{\circ} \mathrm{C}$ under no-load condition and then loaded to the desired stress at a strain rate of $10^{-2} / \mathrm{sec}$, in the austenitic state. From this stage, three consecutive thermal cycles were conducted at $20^{\circ} \mathrm{C} / \mathrm{min}$ and $5^{\circ} \mathrm{C} / \mathrm{min}$ by cooling the specimen down to $100^{\circ} \mathrm{C}$ and subsequently heating the specimen to a temperature of $500^{\circ} \mathrm{C}$. The results from the thermal cycling at the two stress levels, $400 \mathrm{MPa}$ and $500 \mathrm{MPa}$, are shown in Fig. 2a and Fig. 2b.

From Fig. 2, the non-linear evolution of the deformation after the initial loading at both 400 and $500 \mathrm{MPa}$ indicates that the material creeps in the austenitic state, between $450^{\circ} \mathrm{C}$ 
and $500^{\circ} \mathrm{C}$. Below $450^{\circ} \mathrm{C}$, a linear thermal contraction until the point $\mathrm{B}$ is observed. As the specimen is cooled in the austenitic state, the creep rate and consequently the influence of creep decreases as the temperature reduces during the thermal cycling. At point $\mathrm{B}$, forward transformation initiates and the material undergoes transformation into martensite (point C). Upon heating, the reverse transformation begins at $\mathrm{E}$ and the strain recovery initiates. As the temperature is increased to point $F$, the creep rate in the material exceeds the rate of strain recovery resulting in an inflection and subsequent loss of actuation strain. The thermal cycle also results in the generation of rate independent residual strains which are a combination of plastic strain generated over the course of transformation as well as retained martensite. In subsequent cycles a similar behavior is observed, however, with a reduced amount of transformation, plastic and viscoplastic strains. This decrease in the inelastic strains is associated with the plastic and viscoplastic hardening behavior of the material. The material also exhibits larger viscoplastic strain after martensitic phase transformation (upon heating, F to $\mathrm{G}$ ) than the amount observed during the subsequent cooling.

The evolution of the strains due to TRIP effect and the additional effect of retained martensite need to be better understand to develop a constitutive model that will capture such effects. While it is understood that this residual strain (a combination of the TRIP and retained martensite) occurs in each cycle, it still remains unclear if this strain is in fact (i) solely developed during forward transformation, (ii) during the reverse transformation or (iii) distributed between the two in a specific ratio. Thermal cycling tests were conducted with different thermomechanical loading path to better understand the evolution of such residual strains. The maximum test temperature for every test was fixed at $370^{\circ} \mathrm{C}$ for this alloy, to avoid viscoplastic strain contributions. In the first test (shown in Fig. 3a), a specimen is subjected to the following thermomechanical loading path:

1. Heating from room temperature (A) to $370^{\circ} \mathrm{C}(\mathrm{B})$ under a constant compressive stress of $2 \mathrm{MPa}$

2. Loading to a stress level of $400 \mathrm{MPa}\left(\right.$ at $\left.370^{\circ} \mathrm{C}\right)(\mathrm{C})$

3. The stress is kept constant $(400 \mathrm{MPa})$ and the specimen is cooled to $100^{\circ} \mathrm{C}(\mathrm{D})$ at a cooling rate of $20^{\circ} \mathrm{C} / \mathrm{min}$

4. Unloading to a stress level of $2 \mathrm{MPa}\left(\right.$ at $\left.100^{\circ} \mathrm{C}\right)(\mathrm{E})$ 


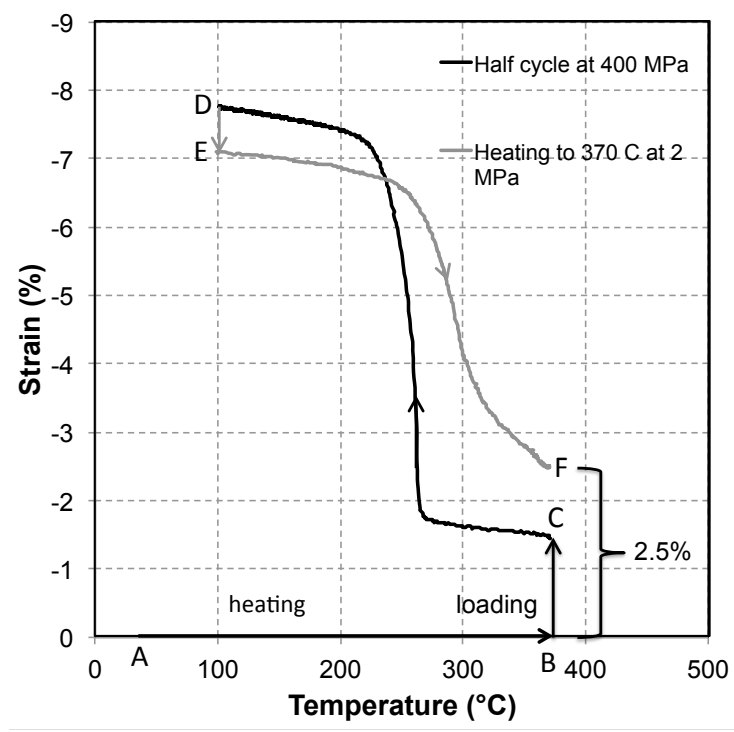

(a)

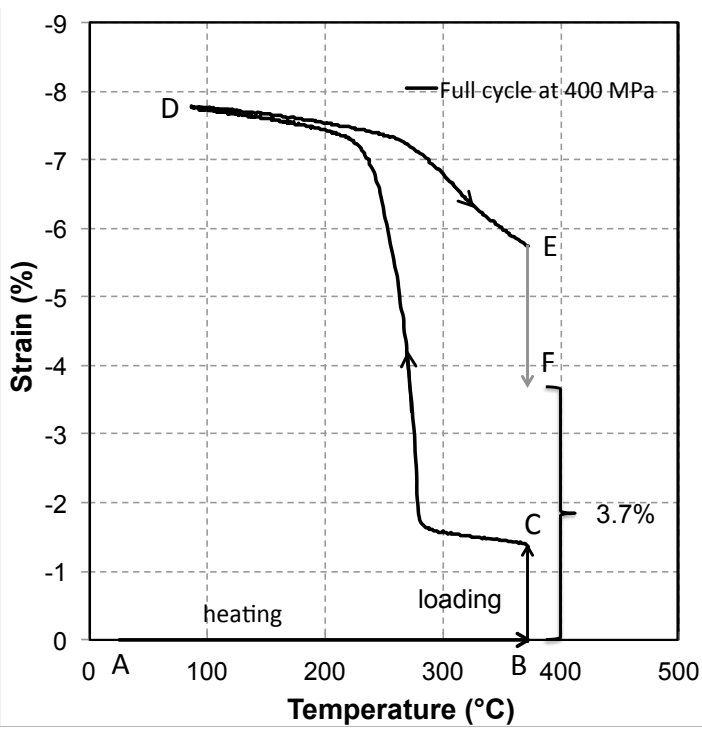

(b)

Figure 3: Strain-temperature diagram showing the residual strain generated in the material upon (a) cooling the material from austenite to martensite under load - unloading - heating to austenite under no load; (b) cooling the material from austenite to martensite and subsequently heating it back to austenite under load - unloading.

5. Heating to $370^{\circ} \mathrm{C}(\mathrm{F})$ at a heating rate of $20^{\circ} \mathrm{C} / \mathrm{min}(\mathrm{s})$

A relative compression $(\sim 2.5 \%)$ of the specimen is measured between the end of step 1 and the end of step 5. This strain represents the residual strain generated in the half thermal cycle, since no additional strain beside thermal expansion is generated during the heating at $2 \mathrm{MPa}$. Indeed, it has been shown that a full thermal cycle under this stress level does not exhibit any irrecoverable strain (Kumar et al., 2011).

For the second test (Fig. 3b), a specimen is subjected to the following thermomechanical cycle:

1. Heating from room temperature (A) to $370^{\circ} \mathrm{C}(\mathrm{B})$ under a constant compressive stress of $2 \mathrm{MPa}$

2. Loading to a stress level of $400 \mathrm{MPa}\left(\right.$ at $\left.370^{\circ} \mathrm{C}\right)(\mathrm{C})$

3. The stress is kept constant ( $400 \mathrm{MPa})$ and the specimen is cooled to $100^{\circ} \mathrm{C}(\mathrm{D})$ at a cooling rate of $20^{\circ} \mathrm{C} / \mathrm{min}(\mathrm{s})$

4. Heating to $370^{\circ} \mathrm{C}(\mathrm{E})$ at a heating rate of $20^{\circ} \mathrm{C} / \mathrm{min}(\mathrm{s})$ 
5. Unloading to a stress level of $2 \mathrm{MPa}\left(\right.$ at $\left.370^{\circ} \mathrm{C}\right)(\mathrm{F})$

A relative compression $(\sim 3.7 \%)$ of the specimen is measured between the end of step 1 and the end of step 5, and represents the the total strain generated in the complete thermal cycle. By comparing the strain generated from the first test and the second test, it is observed that two thirds of the residual strain is generated during the forward transformation and one third is generated during the reverse transformation. The additional tests conducted are utilized to characterize the material behavior at high temperature under high stress level, where large viscoplastic strain, TRIP strains and strain due to retained martensite are exhibited. These tests are unavoidable to determine the evolution of such strains under such thermomechanical conditions. A complete list of all the different tests conducted in the experimental section that are utilized for the characterization of the selected HTSMA alloy is summarized in the following Table 1.

Table 1: List of tests conducted for the calibration of the HTSMA model

\begin{tabular}{cccc}
\hline \hline Test \# & Test type & Test details & Source \\
\hline 1 & Thermal cycling & $0 \mathrm{MPa}, 10^{\circ} \mathrm{C} / \mathrm{min}$ & Kumar et al. (2011) \\
\hline $2-3$ & Uniaxial loading & $185^{\circ} \mathrm{C}$ and $295^{\circ} \mathrm{C}$, at $10^{-4} / \mathrm{sec}$ & Kumar et al. (2011) \\
$4-6$ & Creep tests & 100,300 and $500 \mathrm{MPa}$ at $300^{\circ} \mathrm{C}$ & Kumar et al. (2011) \\
$7-9$ & Creep tests & 100,300 and $500 \mathrm{MPa}$ at $400^{\circ} \mathrm{C}$ & Kumar et al. (2011) \\
$10-12$ & Creep tests & 100,300 and $500 \mathrm{MPa}$ at $500^{\circ} \mathrm{C}$ & Kumar et al. $(2011)$ \\
$13-14$ & Uniaxial loading & 400 and $500^{\circ} \mathrm{C}$, at $10^{-4} / \mathrm{sec}$ & Figure 1 \\
$15-16$ & Thermal cycling & 400 and $500 \mathrm{MPa}$ at $20^{\circ} \mathrm{C} / \mathrm{min}$ & Figure 2 \\
$17-18$ & Thermal cycling & Half cycle and a complete cycle at $400 \mathrm{MPa}$ & Figure 3 \\
\hline
\end{tabular}

\section{3-D Thermomechanical Model for Cyclic Response of HTSMAs}

The proposed thermomechanical model is based on the framework of simultaneous creep and transformation models, initiated by Lagoudas et al. (2009) in 1-D, and extended in 3-D by Hartl et al. (2010b). The derivation of the proposed model is based on an internal state variables approach and begins with the description of a free energy potential. In order to 
capture the mechanisms observed in the thermal cyclic tests of Fig. 2, the proposed free energy potential needs to include the effects of i) the martensitic phase transformation, ii) the transformation-induced, rate independent plasticity (denoted here as TRIP) and iii) the rate-dependent plasticity. A Gibbs free energy is expressed as a function of the external state variables (applied stress tensor $\boldsymbol{\sigma}$ and absolute temperature $T$ ), and a set of internal state variables $\zeta$ representative of the internal state of the considered system. The phase transformation mechanism is assumed to be described by the following set of internal variables: the martensitic volume fraction $\xi$, the transformation strain tensor $\varepsilon^{t}$ and the transformation hardening energy $g^{t}$. Transformation induced plasticity requires the inclusion of the transformation-induced plastic strain tensor $\varepsilon^{t p}$ as an additional internal state variable. To describe the viscoplastic effects, the viscoplastic strain tensor $\varepsilon^{v p}$, the accumulated viscoplastic strain $p$ and the viscoplastic hardening energy $g^{v p}$, which is essential for the description of the hardening behavior of the HTSMA at 400 and $500^{\circ} \mathrm{C}$ (Fig. 1b), are introduced in the internal state variables set. The Gibbs free energy is decomposed into three contributions and written as:

$$
\begin{gathered}
G(\boldsymbol{\sigma}, T, \zeta)=(1-\xi) G_{t e}^{A}(\boldsymbol{\sigma}, T)+\xi G_{t e}^{M}(\boldsymbol{\sigma}, T) \\
+G^{m i x}(\boldsymbol{\sigma}, T, \zeta)
\end{gathered}
$$

where $G_{t e}^{A}$ and $G_{t e}^{M}$ represent the thermoelastic energy terms of austenite and martensite, respectively, while $G^{m i x}$ is the mixing energy term. The thermoelastic Gibbs free energy of each phases is:

$$
\begin{aligned}
G_{t e}^{\gamma}(\boldsymbol{\sigma}, T)= & -\frac{1}{2 \rho} \boldsymbol{\sigma}: \boldsymbol{S}^{\gamma} \boldsymbol{\sigma}-\frac{1}{\rho} \boldsymbol{\sigma}: \boldsymbol{\alpha}\left(T-T_{0}\right) \\
& +c^{\gamma}\left[\left(T-T_{0}\right)-T \ln \left(\frac{T}{T_{0}}\right)\right]-s_{0}^{\gamma} T+u_{0}^{\gamma}, \quad \gamma=A, M,
\end{aligned}
$$

while the mixing energy term contains the contribution of the different inelastic strain mechanisms:

$$
G^{m i x}(\boldsymbol{\sigma}, T, \zeta)=-\frac{1}{\rho} \boldsymbol{\sigma}:\left(\varepsilon^{t}+\varepsilon^{t p}\right)+\frac{1}{\rho} g^{t}-\frac{1}{\rho} \boldsymbol{\sigma}: \varepsilon^{v p}+\frac{1}{\rho} g^{v p}
$$


Assuming the additive decomposition of the thermoelastic components of austenite and martensite, the elastic compliance tensor $\mathcal{S}$, the specific entropy $s_{0}$ and the specific internal energy $u_{0}$ of the two-phase material are defined by the rule of mixtures: $S=S^{A}+\xi\left(S^{M}-S^{A}\right)$. The density $\rho$, the thermal expansion tensor $\boldsymbol{\alpha}$ and the specific heat $c$ are assumed to be the same for both phases. $T_{0}$ denotes a reference temperature at which the thermal expansion strain is set to be zero. Combining the first and second law of thermodynamics, the strong form of the second law is written as ${ }^{1}$

$$
-\rho \dot{G}-\dot{\sigma}: \varepsilon-\rho s \dot{T} \geq 0
$$

Using the forms employed by Lagoudas and Entchev (2004a), both the rate of transformation strain and the rate of TRIP strain are assumed to be proportional to the rate of the martensitic volume fraction $\dot{\xi}$ :

$$
\dot{\varepsilon}^{t}=\Lambda^{t} \dot{\xi}, \quad \dot{\varepsilon}^{t p}=\Lambda^{t p} \dot{\xi}
$$

where $\Lambda^{t}$ is the transformation direction tensor and $\boldsymbol{\Lambda}^{t p}$ is the TRIP direction tensor. The transformation strain direction strain tensor $\boldsymbol{\Lambda}^{t}$ is given as:

$$
\Lambda^{t}= \begin{cases}\Lambda_{f w d}^{t}, & \dot{\xi}>0 \\ \Lambda_{r e v}^{t}, & \dot{\xi}<0\end{cases}
$$

where $\boldsymbol{\Lambda}_{f w d}^{t}$ is the transformation direction tensor during the forward transformation and $\boldsymbol{\Lambda}_{\text {rev }}^{t}$ is transformation direction tensor during the reverse. The form of these tensors are defined as (cf. Bo and Lagoudas (1999a) and Lagoudas and Bo (1999))

$$
\Lambda_{f w d}^{t}=\frac{3}{2} H^{c u r} \frac{\boldsymbol{\sigma}^{\prime}}{\bar{\sigma}}, \quad \quad \boldsymbol{\Lambda}_{r e v}^{t}=\frac{\varepsilon^{t-r}}{\xi^{r}} .
$$

In the above, $\sigma^{\prime}$ is the deviatoric part of the stress tensor, $\bar{\sigma}=\sqrt{3 / 2 \sigma^{\prime}: \boldsymbol{\sigma}^{\prime}}$ is the von Mises equivalent stress, $H^{c u r}=H^{c u r}(\bar{\sigma})$ is the transformation strain magnitude, $\varepsilon^{t-r}$ is the transformation strain at the transformation reversal and $\xi^{r}$ is the martensitic volume fraction at the transformation reversal.

\footnotetext{
${ }^{1}$ the symbol $\dot{x}$ denotes total derivative of the quantity $x$ with respect to time.
} 
Fig. 2 indicates that the transformation strain magnitude of the examined HTSMA material depends on the applied stress. Lagoudas and Bo (1999) introduced a dependency of the transformation strain magnitude as a function of the stress magnitude. In this work, we utilize the empirically motivated exponential evolution of $H^{c u r}$ of Hartl et al. (2010a):

$$
H^{c u r}(\bar{\sigma})=\left\{\begin{array}{cc}
H^{m i n}, & \bar{\sigma}<\bar{\sigma}_{c r i t} \\
H^{m i n}+\left(H^{s a t}-H^{m i n}\right)\left(1-e^{-k\left(\bar{\sigma}-\bar{\sigma}_{c r i t}\right)}\right), & \bar{\sigma} \geqslant \bar{\sigma}_{c r i t}
\end{array}\right.
$$

In this equation, $H^{\text {min }}$ represents the observed uniaxial transformation strain at zero stress level, and $H^{\text {sat }}$ corresponds to the maximum transformation strain for a uniaxial loading at sufficiently high stress level. $\bar{\sigma}_{\text {crit }}$ is the critical von Mises equivalent stress below which $H^{\text {cur }}=H^{\text {min }}$. The parameter $\mathrm{k}$ is used for the calibration of the evolution of $H^{\text {cur }}$ from $H^{\text {min }}$ to $H^{\text {sat }}$ for the applied stress levels above $\bar{\sigma}_{\text {crit }}$.

The TRIP strain is assumed to be dependent on the the history of the martensitic phase transformation, precisely the evolution of stress-oriented detwinned martensite volume fraction (Bo and Lagoudas (1999b)). The detwinned volume fraction can be defined as:

$$
\xi^{d}=\frac{H^{c u r}}{H^{s a t}} \xi
$$

To describe the cyclic evolution of the plastic strain, the accumulated detwinned martensite volume fraction is defined by Bo and Lagoudas (1999b) as:

$$
\zeta^{d}=\int_{0}^{t}\left|\dot{\xi}^{d}(\tau)\right| d \tau
$$

The form of TRIP direction tensor is assumed to be dependent on this accumulated detwinned martensite volume fraction, and the following form is proposed, motivated by the work of Lagoudas and Entchev (2004a):

$$
\dot{\varepsilon}^{t p}=\Lambda^{t p} \dot{\xi}, \quad \Lambda^{t p}=\left\{\begin{array}{cc}
\Lambda_{f w d}^{t p}, & \dot{\xi}>0, \\
\Lambda_{r e v}^{t p}, & \dot{\xi}<0 .
\end{array}\right.
$$

In the above, the $\boldsymbol{\Lambda}_{f w d}^{t p}$ is the TRIP direction tensor during the forward transformation and 
$\Lambda_{r e v}^{t p}$ the form during the reverse. These two tensors are defined as

$$
\begin{gathered}
\Lambda_{f w d}^{t p}=\frac{3}{2} \frac{\sigma^{\prime}}{\bar{\sigma}} w_{1}\left(C_{0}^{t p}+C_{1}^{t p} e^{-\zeta^{d} / C_{2}^{t p}}\right) \frac{H^{c u r}}{H^{s a t}}, \\
\Lambda_{r e v}^{t p}=-\frac{\varepsilon^{t-r}}{\varepsilon^{t-r}}\left(1-w_{1}\right)\left(C_{0}^{t p}+C_{1}^{t p} e^{-\zeta^{d} / C_{2}^{t p}}\right) \frac{H^{c u r}}{H^{s a t}} .
\end{gathered}
$$

In equation (3.12), $C_{0}^{t p}=C_{0}^{t p}(\bar{\sigma})$ and $C_{1}^{t p}=C_{1}^{t p}(\bar{\sigma})$ are stress dependent functions and $C_{2}^{t p}$ is a constant model parameter. The parameter $w_{1}$, which is motivated by the experimental curves of Fig. 3, describes the ratio of the TRIP strain that is generated during forward transformation according to the TRIP strain generated for a full cycle. The functions $C_{1}^{t p}$ and $C_{2}^{t p}$ describe the exponential evolution of the TRIP strains at the first cycles, until the steadystate evolution is reached, as proposed by Lagoudas and Entchev (2004a). Additionally, the proposed evolution law (3.12) is based on the assumption that the TRIP strain in HTSMAs does not have a saturation value. Instead, after several cycles, it evolves linearly with the accumulated detwinned martensitic volume fraction. $C_{0}^{t p}$ describes this linear evolution of the TRIP strain for each cycle, which corresponds to a steady-state ratcheting effect.

The proposed model also considers the effect of the retained martensite that does not transform back into austenite at the conventional martensite $\rightarrow$ austenite transformation stress/temperature state. This volume of martensite is pinned due to the appearance of plastic deformation during martensitic transformation, as observed experimentally by Kumar and Lagoudas (2010) in $N i T i P d_{40}$ HTSMAs. Thus, the transformation strain associated with this volume fraction of retained martensite can not be recovered upon heating. The following evolution equation for the volume fraction of retained martensite, similar to the evolution equation of TRIP strain is proposed:

$$
\dot{\xi}^{R}=\left\{\begin{array}{cc}
w_{2} C_{1}^{R} e^{-\zeta^{d} / C_{2}^{R}} \dot{\zeta}^{d}, & \dot{\xi}>0, \\
\left(1-w_{2}\right) C_{1}^{R} e^{-\zeta^{d} / C_{2}^{R}} \dot{\zeta}^{d}, & \dot{\xi}<0 .
\end{array}\right.
$$

In equation (3.13), $C_{1}^{R}=C_{1}^{R}(\bar{\sigma})$ is a stress dependent function and $C_{2}^{R}$ is a constant model parameter. Due to experimental observations (Fig. 3), the parameter $w_{2}$ is required in order to describe the different evolution of retained martensite between forward and reverse transformation. 
The final variable related to the phase transformation, the transformation hardening energy $g^{t}$, is given by an evolution equation of the form, motivated by Lagoudas (2008), which in the proposed form includes the effect of retained martensite:

$$
\dot{g}^{t}=f^{t} \dot{\xi}, \quad f^{t}= \begin{cases}f_{\text {fwd }}^{t}, & \dot{\xi}>0, \\ f_{\text {rev }}^{t}, & \dot{\xi}<0,\end{cases}
$$

where

$$
\begin{aligned}
f_{f w d}^{t}(\xi) & =\frac{1}{2} a_{1}\left(1+\xi^{n_{1}}-(1-\xi)^{n_{1}}\right)+a_{3}, \\
f_{\text {rev }}^{t}(\xi) & =\frac{1}{2} a_{2}\left(1+\xi^{n_{2}}-(1-\xi)^{n_{2}}\right)-a_{3} .
\end{aligned}
$$

In the above relations, $a_{1}, a_{2}, a_{3}, n_{1}$ and $n_{2}$ are material parameters. Note that when a full thermomechanical cycle is considered, the martensitic volume fraction $\xi$ varies from the current value of $\xi^{R}$ to 1 .

Considering the viscoplastic mechanism, it is assumed that an equivalent accumulated plastic strain, $p$, and the viscoplastic hardening energy will be used as internal variables. The following evolution law of the viscoplastic hardening energy is assumed:

$$
\dot{g}^{v p}=f^{v p} \dot{p},
$$

where $f^{v p}$ is a scalar function of $p$ of the form (Lemaitre and Chaboche, 2002)

$$
f^{v p}=Q_{1} p+Q_{2}\left(1-e^{-Q_{3} p}\right),
$$

and $Q_{1}=Q_{1}(T), Q_{2}=Q_{2}(T)$ and $Q_{3}=Q_{3}(T)$ are temperature dependent model parameters. Note that the exponential term of this hardening function is characteristic of the so-called primary creep mechanism, while the linear term $Q_{1} p$ is characteristic of the viscoplastic hardening.

It is further assumed that the viscoplastic strain rate $\dot{\boldsymbol{\varepsilon}}^{v p}$ and the rate of the equivalent accumulated viscoplastic strain rate $\dot{p}$ are related through the following evolution equation (Lemaitre and Chaboche, 2002): 


$$
\dot{\varepsilon}^{v p}=\Lambda^{v p} \dot{p}, \quad \Lambda^{v p}=\frac{3}{2} \frac{\sigma^{\prime}}{\bar{\sigma}}
$$

where $\Lambda^{v p}$ is the viscoplastic direction tensor.

With regard to the rate dependent viscoplastic mechanism, we identify an appropriate evolution equation for the rate of the equivalent viscoplastic strain $p$ of the form (Lemaitre and Chaboche, 2002) ${ }^{2}$

$$
\dot{p}=\left\langle\frac{\bar{\sigma}-f^{v p}-Y^{v p}}{K_{a}}\right\rangle^{N_{a}},
$$

where $Y^{v p}=Y^{v p}(T)$ is the temperature dependent elastic limit after which creep occurs, $K_{a}=K_{a}(T)$ is the "drag stress" and $N_{a}=N_{a}(T)$ is the "stress exponent". Both are assumed to be temperature-dependent model parameters.

To model the difference observed between the viscoplastic strain rates at the end of the reverse transformation and before the beginning of the forward transformation in the subsequent cycle, it is assumed that each time the material reaches the martensitic phase, the primary creep part of the viscoplastic strain is re-initialized. Specifically, when the material is in the martensitic state, the viscoplastic strain that corresponds to primary creep is removed from the total accumulated viscoplastic strain $p$ in the expression of the viscoplastic hardening function (3.18).

Taking into account the proposed evolution equations, the second law of thermodynamics leads to

$$
\left[\boldsymbol{\sigma}:\left(\Lambda^{t}+\Lambda^{t p}\right)-\rho \partial_{\xi} G-f^{t}\right] \dot{\xi}+\left(\boldsymbol{\sigma}: \Lambda^{v p}-f^{v p}\right) \dot{p} \geq 0
$$

A last assumption of the model is to assume that transformation and viscoplasticity are independent and both strongly dissipative. This assumption is supported by the hysteresis exhibited by standard SMA materials and the dissipative nature of the rate-dependent plasticity. Under this assumption we can write

$$
\begin{gathered}
\left(\boldsymbol{\sigma}:\left(\boldsymbol{\Lambda}^{t}+\boldsymbol{\Lambda}^{t p}\right)-\rho \partial_{\xi} G-f^{t}\right) \dot{\xi}=\pi^{t} \dot{\xi} \geq 0, \\
\left(\boldsymbol{\sigma}: \boldsymbol{\Lambda}^{v p}-f^{v p}\right) \dot{p}=\pi^{v p} \dot{p} \geq 0 .
\end{gathered}
$$

\footnotetext{
${ }^{2}$ the symbol $\langle\cdot\rangle$ denotes the Macaulay brackets defined by the relation $\langle x\rangle=\frac{x+|x|}{2}$
} 
Using the procedure of Coleman and Noll (1963), the following relations for the total infinitesimal strain and entropy are obtained:

$$
\begin{aligned}
& \boldsymbol{\varepsilon}=-\rho \partial \boldsymbol{\sigma} G=\mathcal{S}: \boldsymbol{\sigma}+\boldsymbol{\alpha}\left(T-T_{0}\right)+\boldsymbol{\varepsilon}^{t}+\varepsilon^{t p}+\boldsymbol{\varepsilon}^{v p}, \\
& s=-\partial_{T} G=\frac{1}{\rho} \boldsymbol{\alpha}: \boldsymbol{\sigma}+c \ln \left(\frac{T}{T_{0}}\right)+s_{0} .
\end{aligned}
$$

The total strain tensor is thus additively decomposed into five terms: the elastic strain $\boldsymbol{\varepsilon}^{e}$, the thermal strain $\boldsymbol{\varepsilon}^{\text {th }}$, the recoverable strain due to transformation (or transformation strain) $\varepsilon^{t}$, the irrecoverable strain induced during transformation (TRIP strain) $\varepsilon^{t p}$ and the viscoplastic strain $\varepsilon^{v p}$.

The remaining dissipative terms resulting from the above application of the second law (Clausius-Planck inequality) consist of the partial derivatives of $G$ with respect to each independent internal variable. Two unique critical thermodynamic driving forces are required to define the onset and termination of forward and reverse transformation. These two transformation functions are denoted $\Phi_{f w d}^{t}(\boldsymbol{\sigma}, T, \xi)$ and $\Phi_{r e v}^{t}(\boldsymbol{\sigma}, T, \xi)$ for the forward and reverse transformation, respectively.

The definition of a transformation surface $\Phi_{f w d}^{t}$ :

$$
\Phi_{f w d}^{t}=\pi_{f w d}^{t}-Y_{f w d}^{t}
$$

implies the following Kuhn-Tucker conditions,

$$
\dot{\xi} \geq 0, \quad \Phi_{f w d}^{t} \leq 0, \quad \Phi_{f w d}^{t} \dot{\xi}=0
$$

Specifically, the following form of $Y_{f w d}^{t}$ is assumed (Hartl et al., 2010b)

$$
Y_{f w d}^{t}(\boldsymbol{\sigma})=Y_{0}^{t}+D \boldsymbol{\sigma}:\left(\Lambda_{f w d}^{t}+\Lambda_{f w d}^{t p}\right)
$$

where $D$ is an additional model parameter that captures the stress dependency of the critical thermodynamical force and $Y_{0}^{t}$ is a constant.

Similarly, the reverse phase transformation function $\Phi_{r e v}^{t}$ is defined as

$$
\Phi_{r e v}^{t}=-\pi_{r e v}^{t}-Y_{r e v}^{t}
$$


and the Kuhn-Tucker conditions for $\Phi_{\text {rev }}^{t}$ are written as

$$
\dot{\xi} \leq 0, \quad \Phi_{\text {rev }}^{t} \leq 0, \quad \Phi_{\text {rev }}^{t} \dot{\xi}=0
$$

The reverse transformation critical thermodynamic force is assumed to be (Hartl et al., 2010b)

$$
Y_{r e v}^{t}(\boldsymbol{\sigma})=Y_{0}^{t}+D \boldsymbol{\sigma}:\left(\boldsymbol{\Lambda}_{r e v}^{t}+\Lambda_{r e v}^{t p}\right)
$$

\section{Results and discussion}

\subsection{One-Dimensional Reduction and Calibration of the Proposed Model}

The constitutive model described in the previous section consists of 9 equations: (i) the evolution of transformation strain (3.6), (ii) TRIP strain (3.11) (iii) viscoplastic strain (3.19); (iv) the evolution of transformation hardening energy (3.14), (v) irrecoverable volume fraction of martensite (3.13) and (vi) viscoplastic hardening energy (3.17); (vii) the evolution of the equivalent viscoplastic strain (3.20); (viii) the decomposition of strains (3.23); (ix) the Kuhn-Tucker type conditions on transformation (3.26 or 3.29). This set of equation are expressed in the form of a set of 29 total scalar equations, that can be solved for the 29 total scalar unknowns $\left(\sigma, \varepsilon^{t}, \xi, \xi^{R}, g^{v p}, \varepsilon^{t p}, \varepsilon^{v p}, p\right.$, and $\left.g^{v p}\right)$, given a strain and temperature increment.

The calibration of the proposed model requires four different sets of parameters (thermoelastic, viscoplastic, transformation and TRIP). Two isothermal uniaxial loadings at different temperatures are necessary to identify the elastic moduli of martensite and austenite, respectively (tests \#2-3 in Table 1). To ensure that the material is either fully martensitic or fully austenitic, these two tests were conducted at $M_{f^{-}} 50^{\circ} \mathrm{C}$ and $A_{f}+50{ }^{\circ} \mathrm{C}$, respectively. The coefficient of thermal expansion is calibrated from a stress-free heating/cooling cycle through the range of temperatures from $M_{f^{-}} 50^{\circ} \mathrm{C}$ to $M_{f^{-}} 100^{\circ} \mathrm{C}$ and $A_{f}+50{ }^{\circ} \mathrm{C}$ to $A_{f}+$ $100^{\circ} \mathrm{C}$.

Since uniaxial loadings are sufficient for calibration, the model (the set of needed constitutive equations) is reduced to a form where only one stress component and the temperature is applied, e.g. $\boldsymbol{\sigma} \rightarrow \sigma_{11}=\sigma, \boldsymbol{\sigma} \rightarrow \sigma_{i j}=0, i \neq 1$ or $j \neq 1$. 
Thermoelasticity

\begin{tabular}{ccc} 
Model parameters & Symbols & Values \\
\hline Young's modulus of austenite and martensite & $E^{A}, E^{M}$ & 42500,85000 \\
Poisson's ratio & $\nu$ & 0.3 \\
Thermal expansion coefficient & $\alpha$ & $3.10^{-5}$
\end{tabular}

Transformation

Model parameters Symbols Value

\begin{tabular}{ccc} 
Transformation strain magnitude & $H^{\text {cur }}(\bar{\sigma})$ & $\left.0.0015+(0.0325-0.0015) *\left(1-e^{-0.0104\left(\bar{\sigma}-\bar{\sigma}^{c r i t}\right.}\right)\right)$ \\
Hardening parameters & $a_{1}, a_{2}, a_{3}$ & $7.97,23.31,0.25\left(a_{2}-a_{1}\right)$ \\
& $n_{1}, n_{2}$ & $0.25,0.25$ \\
Transformation criteria & $Y_{0}^{t}, D$ & $3.76,0.53$ \\
Transformation force & $\rho \Delta s_{0}, \rho \Delta u_{0}$ & $-0.18,-97.47$ \\
\hline
\end{tabular}

TRIP-related

$\begin{array}{cccc}w_{1} & 2 / 3 & 2 / 3 \\ & C_{0}^{t p}(\bar{\sigma}) & 0.0219 & 0.0338 \\ & C_{1}^{t p}(\bar{\sigma}) & 0.0274 & 0.016 \\ & C_{2}^{t p} & 1.30 & 1.30 \\ \text { Retained martensite } & w_{2} & 2 / 3 & 2 / 3 \\ & C_{1}^{R}(\bar{\sigma}) & 0.20 & 0.20 \\ & C_{2}^{R} & 1.30 & 1.30\end{array}$


Viscoplasticity

Model parameters Symbols $\quad 400^{\circ} \mathrm{C} \quad 500^{\circ} \mathrm{C}$

$\begin{array}{cccc}\text { Drag stress } & K_{a}(T) & 1069 & 1561 \\ \text { Stress exponent } & N_{a}(T) & 4.2 & 5.2 \\ \text { Hardening parameters } & Q_{1}(T) & 1352 & 1561 \\ & Q_{2}(T) & 346 & 696 \\ & Q_{3}(T) & 641 & 1216 \\ \text { Yield limit } & Y^{v p}(T) & 158 & 28\end{array}$

Table 2: Necessary material parameters for the model.

The decomposition of strains (3.23) reduces to ${ }^{3}, \varepsilon_{11}^{t p}=\varepsilon^{t p}, \varepsilon_{11}^{v p}=\varepsilon^{v p}$ :

$$
\varepsilon=\frac{\sigma}{E}+\alpha\left(T-T_{0}\right)+\varepsilon^{t}+\varepsilon^{t p}+\varepsilon^{v p}
$$

where the effective Young modulus is defined according to the properties of each phase (M, martensite, A, austenite):

$$
\frac{1}{E}=\frac{1}{E^{A}}+\xi\left(\frac{1}{E^{M}}-\frac{1}{E^{A}}\right) .
$$

The evolution equations of inelastic strains $(3.6,3.11,3.19)$ reduce to:

$$
\begin{gathered}
\dot{\varepsilon}^{t}=\left\{\begin{array}{cc}
\Lambda_{f w d}^{t} \dot{\xi}, \quad \Lambda_{f w d}^{t}=H^{c u r} \operatorname{sgn}(\sigma), & \dot{\xi}>0 \\
\Lambda_{r e v}^{t} \dot{\xi}, \quad \Lambda_{r e v}^{t}=\frac{\varepsilon^{t-r}}{\xi^{r}}, & \dot{\xi}<0
\end{array}\right. \\
\dot{\varepsilon}^{t p}=\left\{\begin{array}{cc}
\Lambda_{f w d}^{t p} \dot{\xi}, \quad \Lambda_{f w d}^{t p}=\frac{H^{c u r}}{H^{s a t}} w_{1}\left(C_{0}^{t p}+C_{1}^{t p} e^{-\zeta^{d} / C_{2}^{t p}}\right) \operatorname{sgn}(\sigma), & \dot{\xi}>0 \\
\Lambda_{r e v}^{t p} \dot{\xi}, \quad \Lambda_{r e v}^{t p}=-\frac{H^{c u r}}{H^{s a t}}\left(1-w_{1}\right)\left(C_{0}^{t p}+C_{1}^{t p} e^{-\zeta^{d} / C_{2}^{t p}}\right) \operatorname{sgn}\left(\varepsilon^{t-r}\right), & \dot{\xi}<0
\end{array}\right. \\
\dot{\varepsilon}^{v p}=\left\langle\frac{|\sigma|-Q_{1}\left|\varepsilon^{v p}\right|-Q_{2}\left(1-e^{-Q_{3}\left|\varepsilon^{v p}\right|}\right)-Y^{v p}}{K_{a}}\right\rangle^{N_{a}} \operatorname{sgn}(\sigma)
\end{gathered}
$$

\footnotetext{
${ }^{3}$ The following notation is adopted for the uniaxial strain: $\varepsilon_{11}=\varepsilon, \varepsilon_{11}^{t}=\varepsilon^{t}$
} 
The evolution of retained martensite (3.13), transformation energy (3.14) and hardening energy (3.17) remain unchanged. The transformation functions are now expressed as:

$$
\begin{aligned}
\Phi_{f w d}^{t} & =(1-D)\left(\Lambda_{f w d}^{t}+\Lambda_{f w d}^{t p}\right) \sigma+\frac{1}{2}\left(\frac{1}{E^{M}}-\frac{1}{E^{A}}\right) \sigma^{2} \\
& +\rho \Delta s_{0} T-\rho \Delta u_{0}-f_{f w d}^{t}-Y_{0}^{t} \\
\Phi_{r e v}^{t} & =-(1+D)\left(\Lambda_{r e v}^{t}+\Lambda_{r e v}^{t p}\right) \sigma-\frac{1}{2}\left(\frac{1}{E^{M}}-\frac{1}{E^{A}}\right) \sigma^{2} \\
& -\rho \Delta s_{0} T+\rho \Delta u_{0}+f_{r e v}^{t}-Y_{0}^{t} .
\end{aligned}
$$

Material parameters related to viscoplasticity are calibrated first, utilizing creep tests at three different temperature levels $\left(300^{\circ} \mathrm{C}, 400^{\circ} \mathrm{C}\right.$ and $500^{\circ} \mathrm{C}$, tests \#4-12 in Table 1), and uniaxial tests (tests \#13-14 in Table 1). At each temperature level, one uniaxial test and three creep tests were used to calibrate the five parameters $Q_{1}(T), Q_{2}(T), Q_{3}(T), K_{a}(T)$, $N_{a}(T)$, since these properties may be temperature dependent (Lemaitre and Chaboche, 2002). The procedure follows the one proposed by Schwertel and Schinke (1996). The objective is thus to obtain, for each experimental point, a known set of uniaxial values for $\sigma$, $\varepsilon^{v p}$ and $\dot{\varepsilon}^{v p}$ for both uniaxial tests and creep tests. The viscoplastic parameters are obtained at each temperature level. For instance, at $400{ }^{\circ} \mathrm{C}$ and $500^{\circ} \mathrm{C}$, three creep tests and one uniaxial test are utilized, therefore four sets of values that are characteristic of the mechanical behavior (stress $\sigma$, viscoplastic strain $\varepsilon^{v p}$, viscoplastic strain rate $\dot{\varepsilon}^{v p}$ ) enters in the calibration procedure at these two temperatures. A weighted least square minimization procedure is adopted, in which the objective is to minimize the error between the experimental results and the calibrated 1-D model response. In the following results, the weight of creep tests is assumed to be bigger than the weight of uniaxial tests. This weighted identification method is necessary since the focus of the current study is to match the creep response of the alloy during a thermal cycle. Accordingly, the identification of temperature-dependent strain rate is a priority, rather than the identification of the hardening behavior. To ensure that the creep part is correctly captured, a weight ratio of five has been assigned to the creep tests in comparison with uniaxial tests. . This procedure leads to a nonlinear least square problem, which is solved with the help of the Levenberg-Marquardt method (Press et al., 1992). Once 


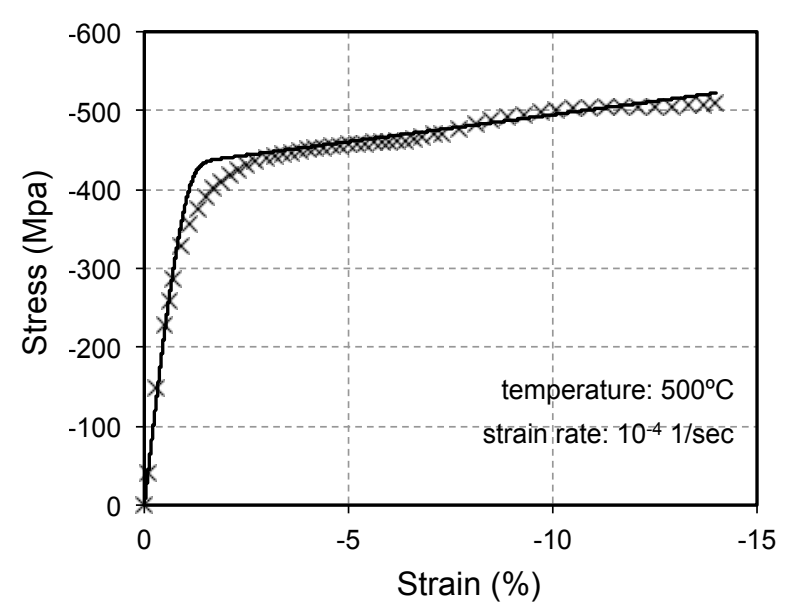

(a)

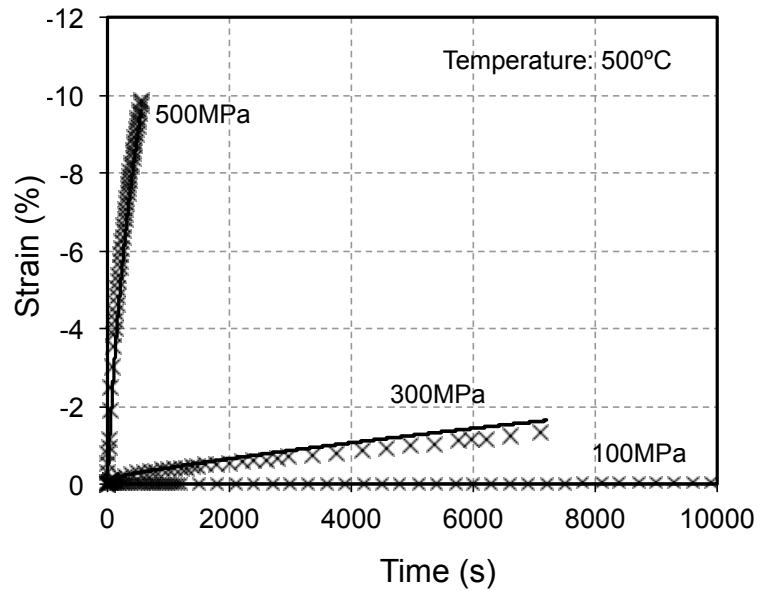

(b)

Figure 4: Comparisons between the simulations of the calibrated model and experimental results at $500{ }^{\circ} \mathrm{Ca}$ ) Uniaxial test b) Creep tests at $300 \mathrm{MPa}$ and $500 \mathrm{MPa}$, respectively.

the parameters at each temperature are determined, a linear evolution of these parameters with respect to the temperature is considered.

To calibrate the model parameters related to the phase transformation, transformationinduced plasticity and the evolution of retained martensite, loading biased cycles at different stress levels are required. Three tests at different stress levels : $0 \mathrm{MPa}, 400 \mathrm{MPa}$ and $500 \mathrm{MPa}$ (experiments \#1, \#15,\#16) are utilized for this purpose. Viscoplastic strains that appear on tests \#15 and \#16 are subtracted using the additive viscoplastic model with the previously calibrated model parameters, and the thermoelastic strains are subtracted based on the thermoelastic parameters already identified. At each stress level, it is therefore possible to obtain the part of the strain that is related to the rate-independent inelastic phenomena. The resultant inelastic strain is composed of contributions from transformation, plasticity induced by transformation and retained martensite. Based on the evolution of these strains at the end of each cooling/heating cycle, the transformation strain magnitude, the transformationinduced plasticity and retained martensite parameters are determined for each stress level and each cycle. Note that for the following simulations, a piecewise linear relationship is utilized to obtain the evolution of the transformation-induced plasticity and retained martensite parameters with respect to the stress magnitude, while the transformation strain magnitude 


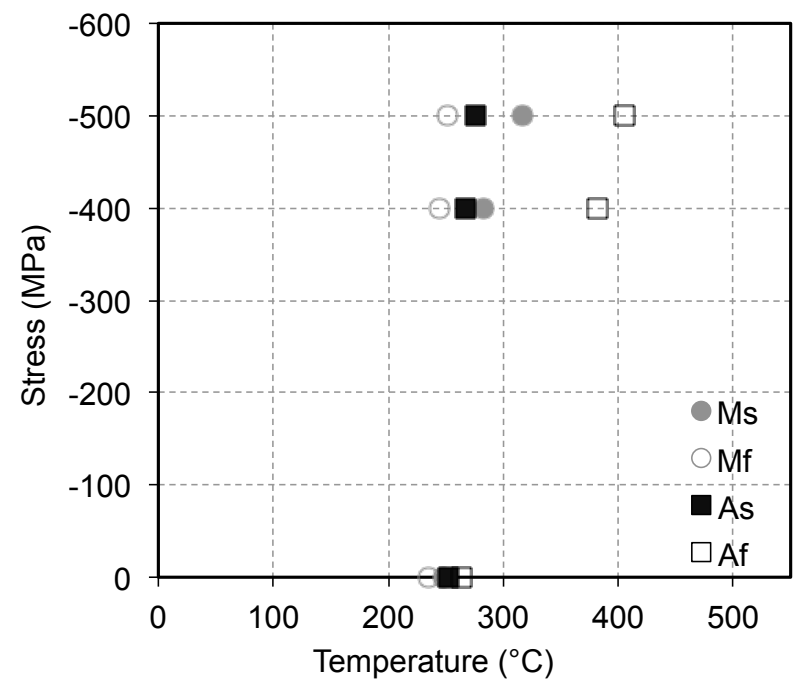

Figure 5: Experimental uniaxial compressive stress - temperature phase diagram for the $T i_{50.5} P d_{30} N i_{19.5}$ HTSMA

evolution is described by an empirically motivated exponential relation (given in eq. 3.8).

An experimental phase diagram is determined based on the transformation temperature obtained from the tangent intersection method applied to the strain-temperature response of the three isobaric tests (at respectively $0 \mathrm{MPa}, 400 \mathrm{MPa}$ and $500 \mathrm{MPa}$ ), performed at a cooling/heating rate of $20^{\circ} \mathrm{C} / \mathrm{min}$, between the thermoelastic regime and the transformation regime (see Fig. 5). From this phase diagram, and the strain magnitude of the transformation strain and TRIP strain, the nine model parameters that enter in the transformation driving force are determined $\left(\rho \Delta s_{0}, \rho \Delta u_{0}, a_{1}, a_{2}, a_{3}, Y_{0}^{t}, D, n_{1}\right.$ and $\left.n_{2}\right)$ using the procedure detailed by Lagoudas et al. (2012).

The comparison between model simulation and experimental results are presented in Fig. 6 for the two load-biased tests performed at $400 \mathrm{MPa}$ and $500 \mathrm{MPa}$ at a cooling/heating rate of $20^{\circ} \mathrm{C} / \mathrm{min}$ (tests \# 15-16, respectively). A good agreement is observed between the calibrated model and the overall evolution of strains that were observed experimentally. It is noted that a discrepancy is observed for the reverse transformation temperature, since the model considers a single slope in the uniaxial stress-temperature phase diagram for the transformation limits that corresponds to the onset and the end of reverse transformation. The value for this single slope has been taken to minimize the discrepancy between the 


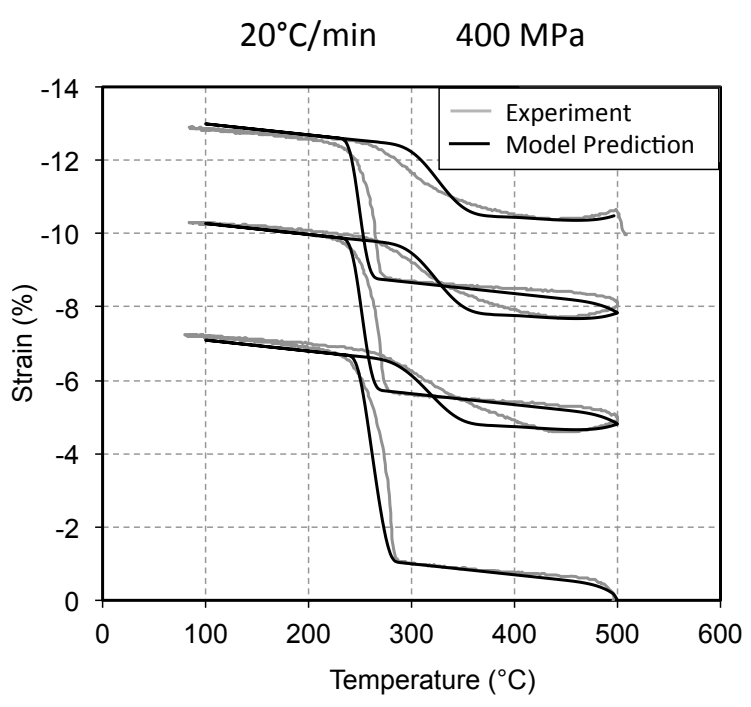

(a)

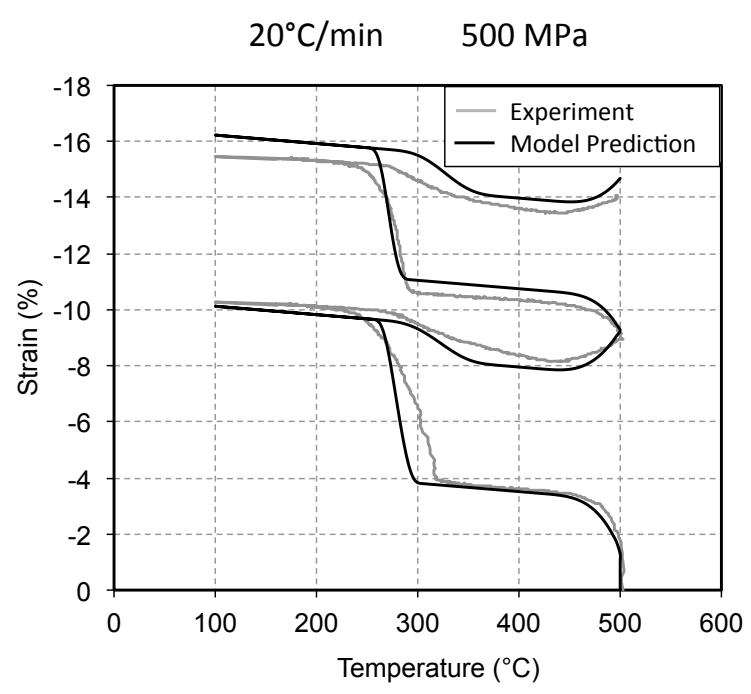

(b)

Figure 6: Comparisons between the model simulations and experimental results for isobaric thermal cycling at a cooling/heating rate of $20^{\circ} \mathrm{C} / \mathrm{min}$ at a) $400 \mathrm{MPa}$ b) $500 \mathrm{MPa}$. Experimental data (grey lines) and current model simulations (black lines) are shown.

calibrated model and the experimental results. Thus, for the forward transformation the average slope between $M_{s}$ and $M_{f}$ was selected, while for the reverse transformation only the slope of $A_{f}$ was used.

\subsection{Numerical Implementation}

To perform numerical simulations of the considered HTSMA behavior, the developed model has been implemented in a Finite Element Analysis software (ABAQUS) as a user material subroutine. The implementation procedure follows the method proposed by Hartl et al. (2010b) for the implementation of a constitutive model that considers the simultaneous occurrence of phase transformation and viscoplasticity. The implementation of the constitutive model consists of the computation of the current stress, based on the total strain and temperature increments. The evolution equations for $\varepsilon^{t}, \xi^{R}, \varepsilon^{t p}$, and $\varepsilon^{v p}$ are integrated over the increment duration. To solve those nonlinear equations, a form of the return mapping algorithm, the convex cutting plane algorithm (Qidwai and Lagoudas, 2000), has been adopted. In the sequel, the index $n$ denotes time step, while the index $k$ refers to the iteration step during a specific time step. 
The computation of the value of the transformation strain, TRIP strain, and viscoplastic strain in the current " $k+1$ "th iteration step depends on the increment of the volume fraction of martensite and the respective current direction tensors:

$$
\begin{gathered}
\boldsymbol{\varepsilon}_{n+1}^{t(k+1)}=\boldsymbol{\varepsilon}_{n}^{t}+\left(\xi_{n+1}^{(k+1)}-\xi_{n}\right) \Lambda^{t}\left(\boldsymbol{\sigma}_{n+1}^{(k)}\right), \\
\boldsymbol{\varepsilon}_{n+1}^{t p^{(k+1)}}=\varepsilon^{t p}{ }_{n}+\left(\xi_{n+1}^{(k+1)}-\xi_{n}\right) \boldsymbol{\Lambda}^{t p}\left(\boldsymbol{\sigma}_{n+1}^{(k)}\right), \\
\boldsymbol{\varepsilon}_{n+1}^{v p(k+1)}=\boldsymbol{\varepsilon}^{v p}{ }_{n}+\Delta t \dot{p}_{n+1}^{(k+1)} \boldsymbol{\Lambda}^{v p}\left(\boldsymbol{\sigma}_{n+1}^{(k)}\right) .
\end{gathered}
$$

The accumulated detwinned martensite volume fraction is updated as

$$
\zeta_{n+1}^{d^{(k+1)}}=\zeta_{n}^{d}+\left(\xi_{n+1}^{(k+1)}-\xi_{n}\right) \xi^{d}
$$

while the irrecoverable part of the volume fraction of martensite is computed as

$$
\xi_{n+1}^{R^{(k+1)}}=\xi_{n}^{R}+\left(\xi_{n+1}^{d^{(k+1)}}-\xi_{n}^{d}\right) \Lambda^{R}
$$

where

$$
\Lambda^{R}=\left\{\begin{array}{cc}
w_{2} C_{1}^{R} e^{-\zeta^{d} / C_{2}^{R},} & \Delta \xi>0, \\
\left(1-w_{2}\right) C_{1}^{R} e^{-\zeta^{d} / C_{2}^{R}}, & \Delta \xi<0 .
\end{array}\right.
$$

The updated values for $\xi$ and $\dot{p}$ are obtained following the method proposed by Hartl et al. (2010b), i.e. satisfying the following two conditions

$$
\Phi_{n+1}^{t^{(k+1)}}=\Phi_{n+1}^{t^{(k)}}+\Delta \Phi_{n+1}^{t^{(k)}} \simeq 0, \quad \Phi_{n+1}^{v p(k+1)}=\Phi_{n+1}^{v p(k)}+\Delta \Phi_{n+1}^{v p(k)} \simeq 0
$$

where

$$
\Phi_{n+1}^{v p(k+1)}=\left\langle\frac{\bar{\sigma}_{n+1}^{(k+1)}-f^{v p}-Y^{v p}}{K_{a}}\right\rangle^{N_{a}}-\dot{p}_{n+1}^{(k)} .
$$

The re-initialization of the primary creep in the expression of the viscoplastic hardening occurs when the material is in a martensitic state. The accumulated viscoplastic strain $p$ is additively decomposed into two contributions: 


$$
p=p_{1}+p_{2}
$$

where $p_{1}$ and $p_{2}$ are the accumulated plastic strains generated during the primary and the secondary creep regime, respectively. The primary creep occurs until the exponential contribution of the viscoplastic hardening energy becomes negligible, i.e.

$$
1-e^{-Q_{3} p} \simeq 0
$$

When the volume fraction of martensite reaches 1 , the accumulated plastic strain $p$ in the expression of the viscoplastic hardening is set to $p_{2}$ to represent the re-initialization of the primary creep. We note though that the re-initialization affects only the viscoplastic hardening function, while the total accumulated viscoplastic strain $p$ retains its value and is not reduced.

\subsection{Prediction of the behavior of a compression specimen}

To determine the model prediction capabilities, two load-biased actuation tests were performed under a constant load that correspond to an average stress of $400 \mathrm{MPa}$ and 500 $\mathrm{MPa}$. These tests were performed in a range of temperatures from $100{ }^{\circ} \mathrm{C}$ to $500^{\circ} \mathrm{C}$. The heating/cooling rate was set to $5^{\circ} \mathrm{C} / \mathrm{min}$. This rate was slow enough to induce significant viscoplastic strains in the HTSMA.

The investigation of the behavior of a compression specimen used for the material characterization is performed using the constitutive model implemented in a Finite Element Analysis software (ABAQUS). According to geometric and loading symmetries, an axisymmetric model is defined, composed of 390 axisymmetric (generalized plane strain) quadratic elements. To describe accurately the time-dependent response of the HTSMA plot, a minimum of 60 time increments per minute is imposed during the heating/cooling steps. Note that a contact condition is imposed at the top and bottom surface of the plot, with an imposed tangential friction. The friction parameter has been measured experimentally and is taken to be 0.2. A comparison between the model predictions and the experimental results is shown in Fig. 7. The model predicts with a good accuracy the overall thermomechanical behavior of the specimen. 


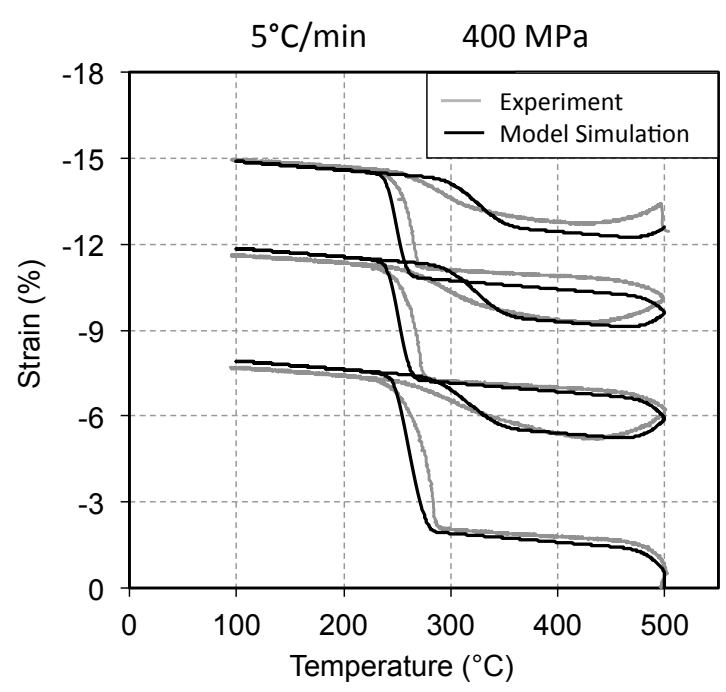

(a)

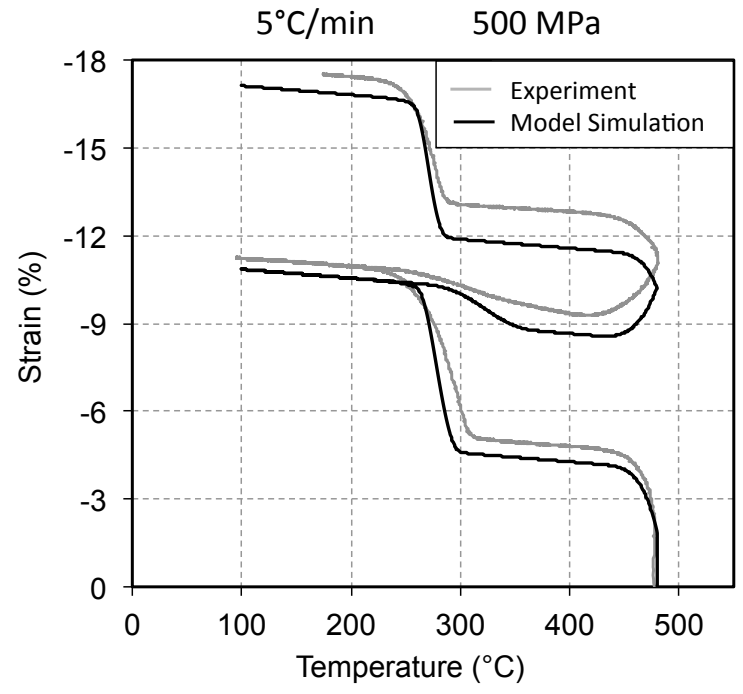

(b)

Figure 7: Comparison between model predictions and experimental compressive stress-strain response under isobaric thermal cycling at a cooling/heating rate of $5^{\circ} \mathrm{C} / \mathrm{min}$ at a) $400 \mathrm{MPa}$ b) $500 \mathrm{MPa}$.

To further investigate the behavior of such a HTSMA actuator (under $400 \mathrm{MPa}$ average stress), the contour plots of the equivalent von Mises stress, the retained martensite volume fraction, the component of the TRIP strain $\varepsilon_{22}^{t p}$, and the component $\varepsilon_{22}^{v p}$ of the viscoplastic strain are shown in Fig. 8 at the end of each of the three cooling/heating cycles. The direction "2" is colinear with the axis of revolution of the compression specimen. These components are characteristic of the non-recoverable strain that is exhibited by the specimen. It is observed that the distribution of the volume fraction of retained martensite is almost constant everywhere in the specimen. However, the TRIP strain and the viscoplastic strain fields are heterogeneous. The TRIP strain magnitude varies from 0.04 to 0.1 at the end of the third cycle, while the viscoplastic strain varies from 0 to 0.06 . The reason for such an heterogeneity is that the friction condition imposed at the top and bottom surface induces an heterogeneity of the stress field (see Fig. 8) throughout the specimen, which modifies the local evolution of the TRIP and viscoplastic strains. Indeed, these two components are strongly dependent on the stress magnitude. The results indicate that the stress-strain behavior obtained experimentally, considering an homogeneous stress state in the material, corresponds to an average value of these quantities over the specimen. FEA analysis of such 
a specimen allows for a better description of the stress state and the evolution of strain inside the specimen.

\subsection{Numerical simulations of a HTSMA wave spring}

To demonstrate the capabilities of the proposed model and to analyze the behavior of three-dimensional structures, we simulate an actuator with a more complex geometry. We consider a HTSMA wave spring, made out of several wave rings stacked on top of each other to create an actuator capable of providing large actuation displacement under significant forces. Specifically, 10 wave collars are considered, with an inner radius of $16.4 \mathrm{~mm}$, an outer radius of $20 \mathrm{~mm}$ and a thickness of $0.195 \mathrm{~mm}$. The total height of the wave spring is $9 \mathrm{~mm}$. The initial geometry of the wave spring is shown in Figure 9.

The FEM model considers a unique set of two antagonist wave collars. Note that this corresponds to $1 / 5$ of the total height of the complete wave spring. The considered thermomechanical loading path is as follows:

1. At $\mathrm{T}=500^{\circ} \mathrm{C}$, an axial compressive load of $10 \mathrm{~N}$ is applied in $10 \mathrm{~s}$

2. Maintaining the biasing load, the wave spring is cooled uniformly to $\mathrm{T}=100^{\circ} \mathrm{C}$ in $80 \mathrm{~min}$, with a constant cooling rate of $5^{\circ} \mathrm{C} / \mathrm{min}$

3. Maintaining the biasing load, the wave spring is heated uniformly to $\mathrm{T}=500{ }^{\circ} \mathrm{C}$ in $80 \mathrm{~min}$, with a constant heating rate of $5^{\circ} \mathrm{C} / \mathrm{min}$

4. Repeat step 2 and 3 (2 times).

A second load path is considered, similar to the first one, except that the cooling/heating rate is set to $20^{\circ} \mathrm{C} / \mathrm{min}$. The biasing load is applied to the wave spring using a rigid plane. A contact condition is imposed between a rigid top plane and the top ring, and between a rigid bottom plane and the bottom ring. Moreover, a contact condition is also imposed between the surfaces of each layer. A tangential friction is considered, with a value of 0.2 for the friction coefficient.

The evolution of the normalized length reduction of the spring (according to its height) with respect to the temperature is shown in Fig. 10. The length reduction due to the applied load is 0.42 of the total height of the spring. It is seen during the first cooling cycle that a cooling rate of $20^{\circ} \mathrm{C} / \mathrm{min}$ and $5^{\circ} \mathrm{C} / \mathrm{min}$ are slow enough to induce viscoplastic strain from 

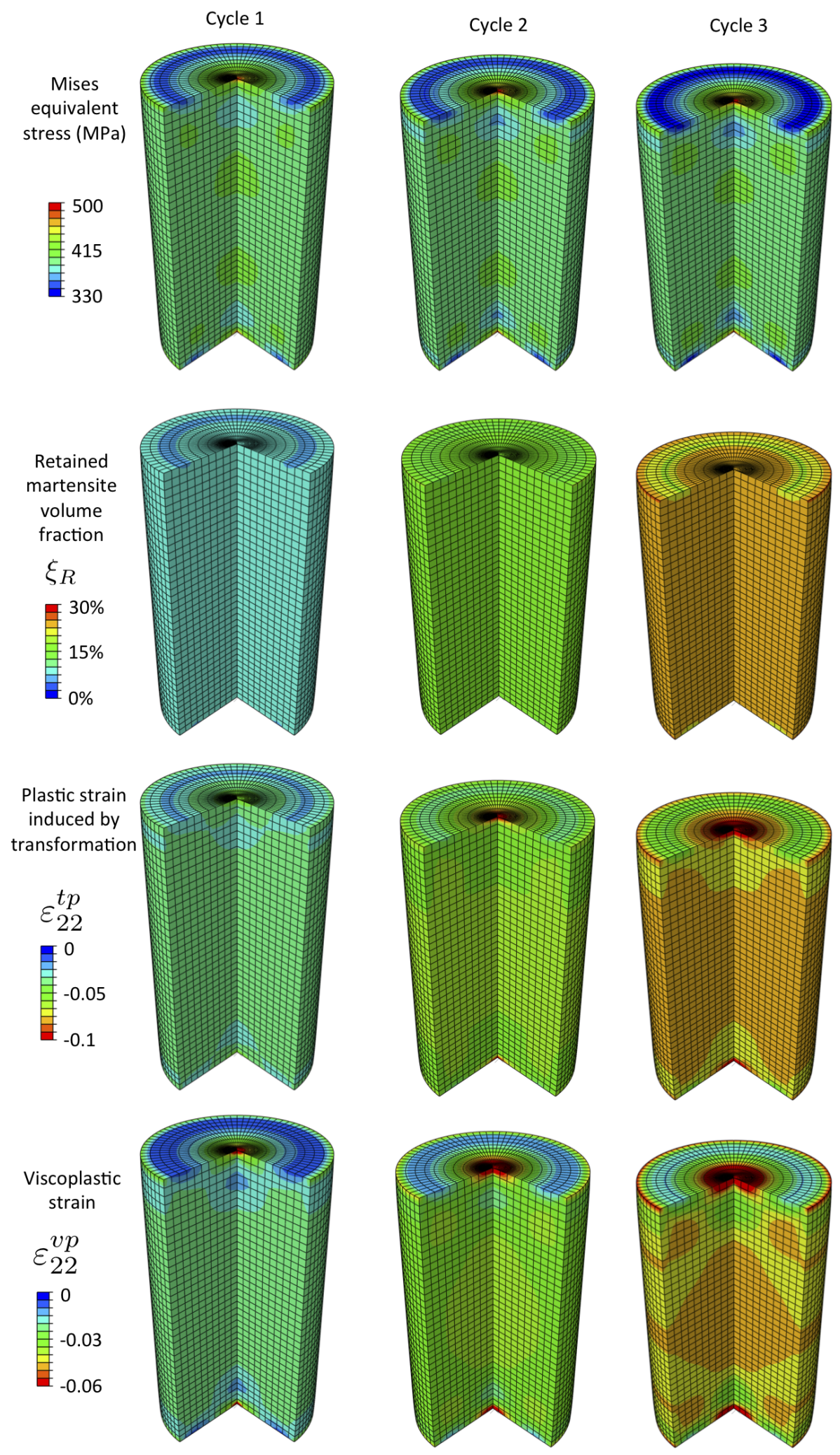

Figure 8: Numerical results of a HTSMA compression plot under under isobaric loading (400 MPa). Representation of the material state at the end of each of the three cooling/heating cycle at $5{ }^{\circ} \mathrm{C} / \mathrm{min}$. 


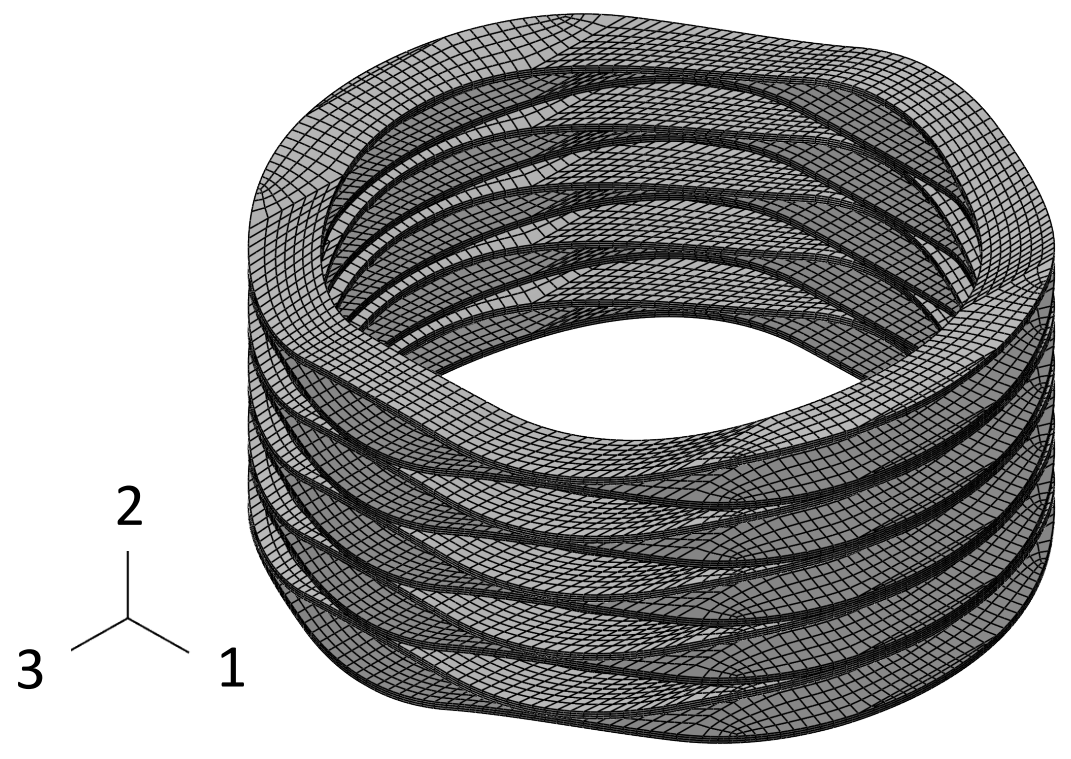

Figure 9: Initial geometry of the wave spring

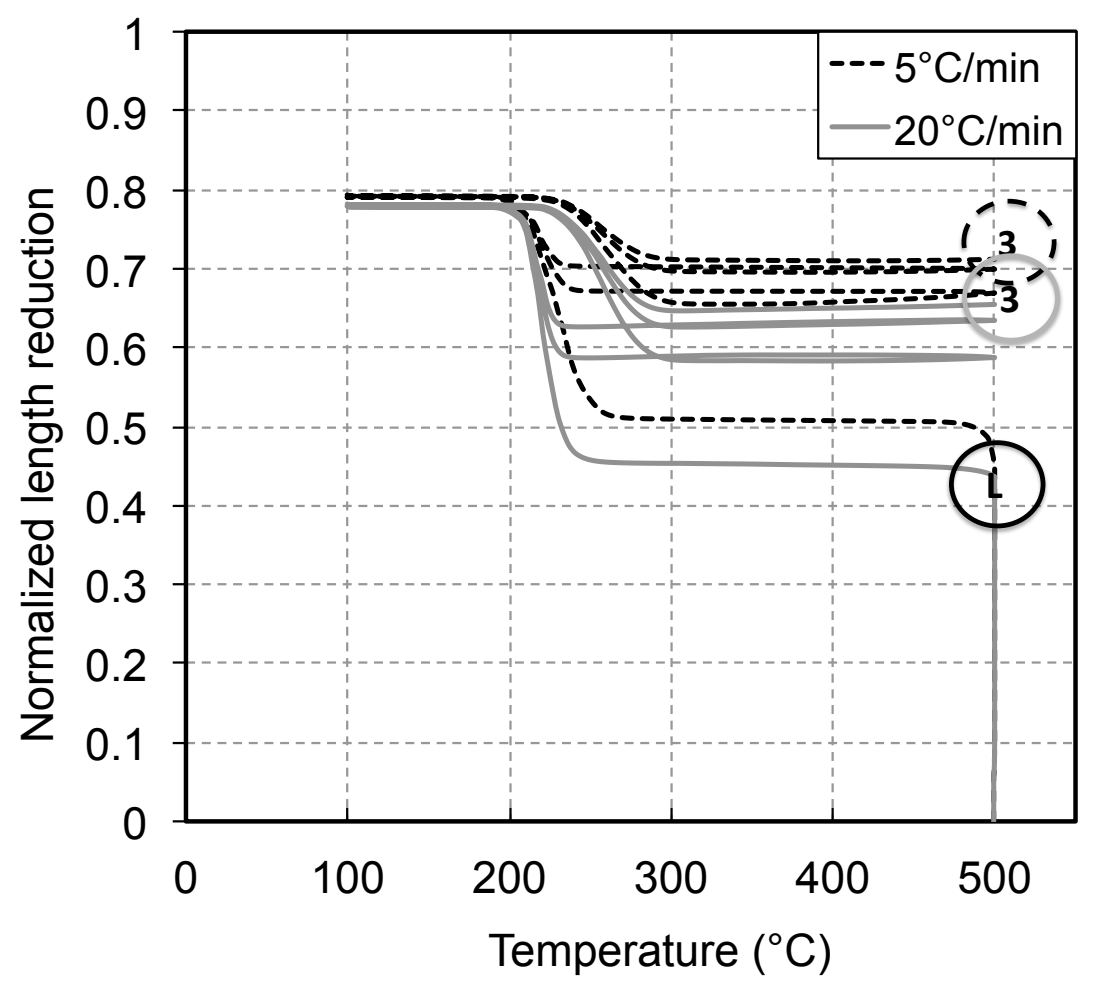

Figure 10: Evolution of the normalized length reduction of the wave spring for two different cooling/heating rates $\left(5^{\circ} \mathrm{C} / \mathrm{min}\right.$ and $\left.20^{\circ} \mathrm{C} / \mathrm{min}\right)$ 
$500^{\circ} \mathrm{C}$ to $400^{\circ} \mathrm{C}$. However the slow cooling rate $\left(5^{\circ} \mathrm{C} / \mathrm{min}\right)$ induce a length reduction of the spring that is significantly higher than the fast cooling rate $\left(20^{\circ} \mathrm{C} / \mathrm{min}\right)$. Indeed, a fast cooling rate results in less creep and thus less overall irrecoverable shape change. Cooling further below $190^{\circ} \mathrm{C}$, the appearance of transformation strain accompanied with TRIP strain induces a large reduction of the spring height. In the two cases, the shape of the spring is very close to a pile of rings that have become totally flat. Below $190{ }^{\circ} \mathrm{C}$, there is no further reduction of the spring height and the spring is in a fully martensitic state. Upon heating, a fraction of the initial length of the spring is recovered as the HTSMA undergoes reverse martensitic transformation. At temperatures higher than $400^{\circ} \mathrm{C}$, additional viscoplastic strain is generated. The irrecoverable nature of the viscoplastic strain, the TRIP strain and the effect of retained martensite induce a change in the geometry of the spring at the reference high temperature $\left(500^{\circ} \mathrm{C}\right)$, with a reduced length according to the initial geometry. During the following cycles, the geometry at the reference high temperature continues to change from cycle to cycle, which means that irrecoverable strains are generated. Actually, the same sequence of the deformation mechanisms appears during the following cycles, however according to what has been observed for the uniaxial behavior, the amount of irrecoverable strain due to TRIP, retained martensite and viscoplasticity is reduced.

Detailed analysis results for the cases of $5{ }^{\circ} \mathrm{C} / \mathrm{min}$ and $20^{\circ} \mathrm{C} / \mathrm{min}$ cooling/ heating rates are provided in Fig. 11. The contour plot of the von Mises stress is provided at the end of the loading stage (denoted by point 'L' in Fig. 10) and at the end of the third cycle (denoted by point '3' in Fig. 10). Both of these points correspond to a spring with a uniform temperature that corresponds to the reference temperature $\left(500^{\circ} \mathrm{C}\right)$. The von Mises stress is similar for the two simulations, since the same loading is applied, fast enough to avoid any creep at $500{ }^{\circ} \mathrm{C}$. At the end of the third cycle, the stress repartition has been modified, with an overall decrease of the stress amplitude throughout the spring. This comes from the change in the spring shape, specifically the wave collars have become more flat, due to the appearance of irrecoverable strains over the three cycles. Thus, due to the differences in the generated irrecoverable strain in the two cases, the same applied load leads to a different stress repartition. The von Mises stress is slightly different between the two simulations with the maximum stress being lower for the slow cooling/heating rate $\left(5^{\circ} \mathrm{C} / \mathrm{min}\right)$. It is also 


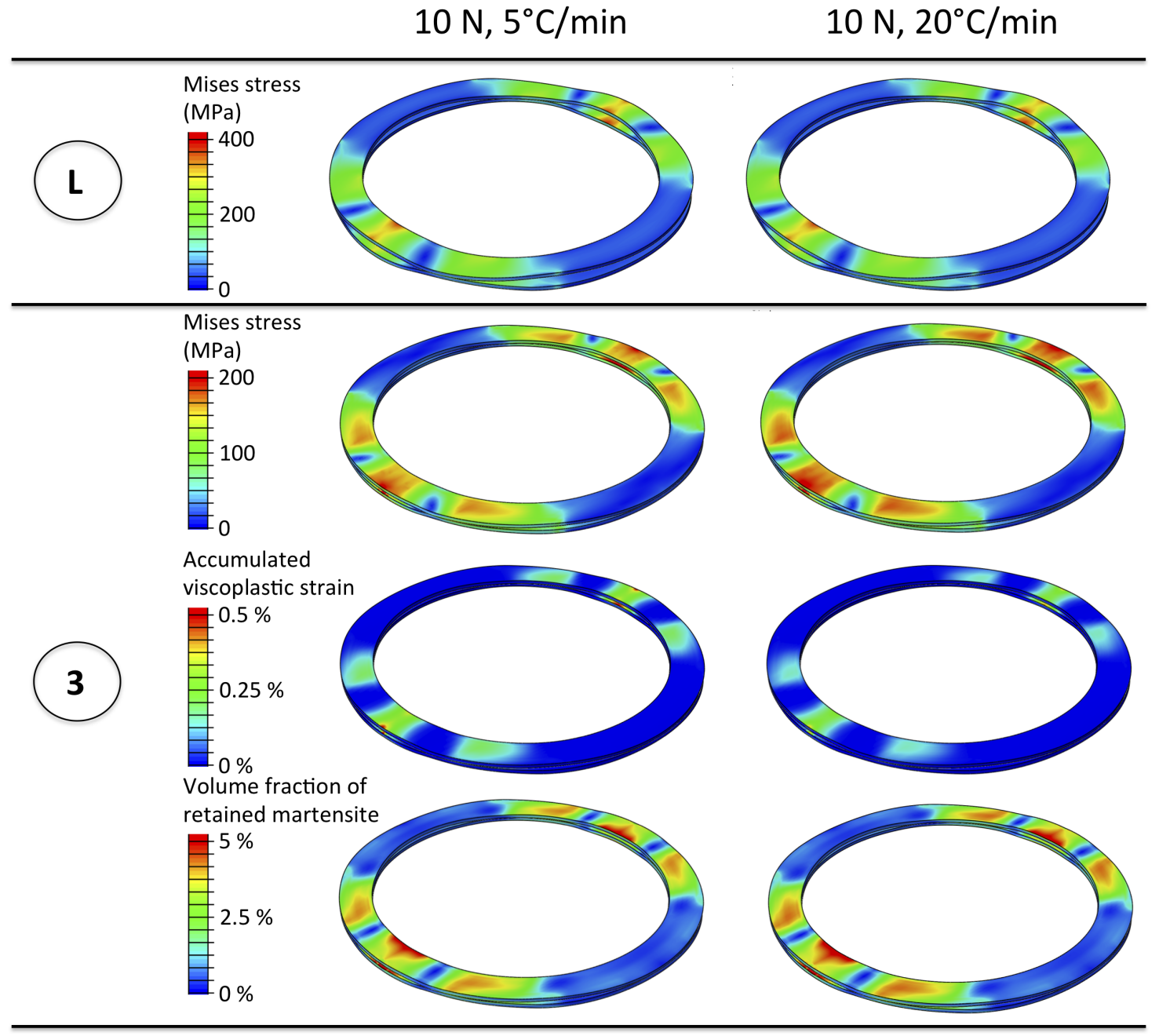

Figure 11: Contour plot, for two antagonist collars, of Mises stress at the end of the application of the load, and contour plot of the Mises stress, the accumulated viscoplastic strain and the volume fraction of retained martensite for two cooling/heating rates $\left(5^{\circ} \mathrm{C} / \mathrm{min}\right.$ and $\left.20^{\circ} \mathrm{C} / \mathrm{min}\right)$ 
observed that the accumulated irrecoverable viscoplastic strain is higher in the case of the slow cooling rate. Interestingly, the amount of retained martensite is reduced in this case. In fact, the amount of irrecoverable viscoplastic strain has induced a more pronounced flat shape during the martensitic transformation (see Fig. 10) at the reference temperature, resulting in an overall lower stress amplitude throughout the wave collars. This reduced stress amplitude induces, during forward transformation, a smaller amount of detwinned martensite. However, the amount of retained martensite depends on the accumulated detwinned martensite volume fraction. Thus, in this case, the amount of retained martensite is reduced.

\section{Conclusions}

The focus of this work is the study of the simultaneous transformation and viscoplastic behavior of high temperature shape memory alloys during multiple thermomechanical cycles. To account for the different deformation mechanisms that occur in the HTSMAs, a new constitutive model is developed. The model accounts for the following mechanisms: viscoplasticity, transformation, plasticity during transformation, and retained martensite. Such mechanisms significantly influence the actuation response and need to be accounted for in the design of HTSMA actuators. A set of experiments related to a calibration procedure have been proposed for a complete characterization of the material behavior. The proposed model, after proper calibration, is able to accurately predict the evolution of the actuation behavior during cyclic loading. Finally, a numerical implementation of the proposed thermomechanical constitutive model allows the solution of complex, time-dependent boundary value problems, for the numerical simulation of the response of HTSMA actuators. Such numerical implementation is highly challenging since many variables are evolving simultaneously. The choice of an efficient algorithm (i.e., the cutting plane algorithm) allows the simulation of HTSMA structures subjected to complex cyclic loadings for industrial applications.

\section{Acknowledgment}

The authors acknowledge the financial support provided by NASA Glenn Research Center, project NNX07AB56A, for this work. We would like to thank Dr. Ronald Noebe for 
helpful discussions. The support of the NSF International Institute of Materials for Energy Conversion (IIMEC), award \#0844082, is acknowledged. The authors would also like to thank Mr. Uri Desai, for performing some of the experiments presented in this paper.

\section{References}

Andersen, A., P. D. S. A., Sangesland, S., July 1999. Detailed study of shape memory alloys in oil well applications. Tech. rep., SINTEF Petroleum Research, Trondheim, Norway.

Bo, Z., Lagoudas, D. C., 1999a. Thermomechanical modeling of polycrystalline SMAs under cyclic loading, Part I: Theoretical Derivations. International Journal of Engineering Science 37, 1089-1140.

Bo, Z., Lagoudas, D. C., 1999b. Thermomechanical modeling of polycrystalline SMAs under cyclic loading, Part III: Evolution of plastic strains and two-way shape memory effect. International Journal of Engineering Science 37, 1175-1203.

Boyd, J., Lagoudas, D. C., 1996. A thermodynamical constitutive model for shape memory materials. Part I: the monolithic shape memory alloy. International Journal of Plasticity $12(6), 805-842$.

Brinson, L. C., 1993. One-dimensional constitutive behavior of shape memory alloys: Thermomechanical derivation with non-constant material functions and redefined martensite internal variable. Journal of Intelligent Material Systems and Structures 4, 229-242.

Cai, W., Tanaka, S., Otsuka, K., 2000. Thermal cyclic characteristics under load in a $T i_{50.6} P d_{30} N i_{19.4}$ alloy. Materials Science Forum 327-328, 279-282.

Chemisky, Y., Duval, A., Patoor, E., Zineb, T. B., 2011. Constitutive model for shape memory alloys including phase transformation, martensitic reorientation and twins accommodation. Mechanics of Materials 43 (7), 361-376.

Coleman, B., Noll, W., 1963. The thermodynamics of elastic materials with heat conduction and viscosity. Archive for Rational Mechanics and Analysis 13, 167-178. 
DeCastro, J. A., Melcher, K. J., Noebe, R. D., 2005. System-level design of a shape memory alloy actuator for active clearance control in the high-pressure turbine. AIAA (3988-4002).

Golberg, D., Xu, Y., Murakami, Y., Morito, S., Otsuka, K., T., U., Horikawa, H., 1994. Improvement of a $T i_{50} P d_{30} N i_{20}$ high-temperature shape memory alloy by thermomechanical treatment. Scripta Metallurgica et Materialia 30 (10), 1349-1354.

Golberg, D., Xu, Y., Murakami, Y., Morito, S., Otsuka, K., T., U., Horikawa, H., 1995a. Characteristics of $T i_{50} P d_{30} N i_{20}$ high-temperature shape memory alloy. Intermetallics 3, $35-46$.

Golberg, D., Xu, Y., Murakami, Y., Otsuka, K., T., U., Horikawa, H., 1995b. Hightemperature shape memory effect in $T i_{50} P d_{50-x} N i_{x}(x=10,15,20)$ alloys. Materials letters $22,241-248$.

Hartl, D., Lagoudas, D., 2009. Constitutive modeling and structural analysis considering simultaneous phase transformation and plastic yield in shape memory alloys. Smart Materials and Structures $18(1-17)$.

Hartl, D., Mooney, J., Lagoudas, D., Calkins, F., Mabe, J., 2010a. Use of a Ni 60 Ti shape memory alloy for active jet engine chevron application: II. experimentally validated numerical analysis. Smart Materials and Structures 19, 015021.

Hartl, D. J., Chatzigeorgiou, G., Lagoudas, D. C., 2010b. Three-dimensional modeling and numerical analysis of rate-dependent irrecoverable deformation in shape memory alloys. International Journal of Plasticity 26 (10), 1485 - 1507.

Khalil, W., Mikolajczak, A., Bouby, C., Ben Zineb, T., 2012. A constitutive model for fe-based shape memory alloy considering martensitic transformation and plastic sliding coupling: Application to a finite element structural analysis. Journal of Intelligent Material Systems and Structures 23, 1143-1160.

Kockar, B., Karaman, I., Kim, J., Chumlyakov, Y., 2006. A method to enhance cyclic reversibility of nitihf high temperature shape memory alloys. Scripta Materialia 54 (12), 2203-2208. 
Kumar, P. K., Desai, U., Monroe, J., Lagoudas, D. C., Karaman, I., Noebe, R., Bigelow, G., 2011. Experimental investigation of simultaneous creep, plasticity and transformation of $\mathrm{Ti}_{50.5} \mathrm{Pd}_{30} \mathrm{Ni}_{19.5}$ high temperature shape memory alloy during cyclic actuation. Materials Science and Engineering A (In Press) 530, 117 - 127.

Kumar, P. K., Lagoudas, D. C., 2010. Experimental and microstructural characterization of simultaneous creep, plasticity and phase transformation in ti50pd40ni10 high-temperature shape memory alloy. Acta Materialia 58 (5), 1618 - 1628.

Lagoudas, D., Hartl, D., Chemisky, Y., Machado, L., Popov, P., 2012. Constitutive model for the numerical analysis of phase transformation in polycrystalline shape memory alloys. International Journal of Plasticity 32-33, 155-183.

Lagoudas, D. C. (Ed.), 2008. Shape Memory Alloys: Modeling and Engineering Applications. Springer.

Lagoudas, D. C., Bo, Z., 1999. Thermomechanical modeling of polycrystalline SMAs under cyclic loading, Part II: Material characterization and experimental results for a stable transformation cycle. International Journal of Engineering Science 37, 1141-1173.

Lagoudas, D. C., Chatzigeorgiou, G., Kumar, P., 2009. Modeling and experimental study of simultaneous creep and transformation in polycrystalline high-temperature shape memory alloys. Journal of Intelligent Material Systems and Structures 20, 2257-2267.

Lagoudas, D. C., Entchev, P., 2004a. Modeling of transformation-induced plasticity and its effect on the behavior of porous shape memory alloys: Part I: Constitutive model for fully dense SMAs. Mechanics of Materials 36 (9), 865-892.

Lagoudas, D. C., Entchev, P. B., 2004b. Modeling of transformation-induced plasticity and its effect on the behavior of porous shape memory alloys. part i: constitutive model for fully dense smas. Mechanics of Materials 36 (9), $865-892$.

Leclercq, S., Lexcellent, C., 1996. A general macroscopic description of the thermomechanical behavior of shape memory alloys. Journal of the Mechanics and Physics of Solids 44 (6), $953-980$. 
Lemaitre, J., Chaboche, J.-L., 2002. Mechanics of solid materials. Cambridge University Press.

Liang, C., Rogers, C. A., 1990. One-dimensional thermomechanical constitutive relations for shape memory materials. Journal of Intelligent Material Systems and Structures 1, $207-234$.

Lidquist, P., Wayman, C. M., 1990. Shape memory and transformation behavior of martensitic $T i-P d-N i$ and $T i-P t-N i$ alloys, Engineering Aspects of Shape Memory Alloys. Butterworth-Heinemann, London.

Lindquist, P., 1988. Structure and transformation behavior of martensite ti-(ni, pd) and ti-(ni, pt) alloys. Ph.D. thesis, Univesity of Illinois at Urbana-Champaign.

Ma, J., Karaman, I., Noebe, R. D., 2010. High temperature shape memory alloys. International Materials Review 55 (59), 257-315.

Noebe, R., Padula II, S., Bigelow, G., Rios, O., A., G., Lerch, B., 2006. Properties of a $N i_{19.5} P d_{30} T i_{50.5}$ high-temperature shape memory alloy in tension and compression. In: Proceedings of SPIE. Vol. 6170. pp. 279-291.

Otsuka, K., Wayman, C. M. (Eds.), 1999. Shape Memory Materials. Cambridge University Press, Cambridge.

Padula II, S., Bigelow, G., Noebe, R., Gaydosh, D., Garg, A., 2006. Challenges and progress in the development of high-temperature shape memory alloys based on NiTiX compositions for high-force actuator applications. In: Proceedings of the International Conference on Shape Memory and Superelastic Technologies. ASM International, Metals Park, OH.

Panico, M., Brinson, L., 2007. A three-dimensional phenomenological model for martensite reorientation in shape memory alloys. Journal of the Mechanics and Physics of Solids 55, $2491-2511$.

Press, W., Teukolsky, S., Vetterling, W., Flannery, B., 1992. Numerical Recipes in C - The Art of Scientific Computing - Second Edition. Cambridge University Press, Cambridge. 
Pu, Z., Tseng, H., Wu, K., 1995. Martensite transformation and shape-memory effect of NiTi-Zr high- temperature shape-memory alloys. In: SPIE proceedings. Vol. 2441. p. 171.

Qidwai, M. A., Lagoudas, D. C., 2000. Numerical implementation of a shape memory alloy thermomechanical constitutive model using return mapping algorithm. International Journal for Numerical Methods in Engineering 47, 1123-1168.

Savi, M., Paiva, A., Baêta-Neves, A. P., Pacheco, P. M. C. L., 2002. Phenomenological modeling and numerical simulation of shape memory alloys: A thermo-plastic-phase transformation coupled model. Journal of Intelligent Material Systems and Structures 13, 261-273.

Schwertel, J., Schinke, B., 1996. Automated evaluation of material parameters of viscoplastic constitutive equations. Journal of Engineering Materials and Technology 118 (3), 273-280.

Sedlak, P., Frost, M., Benesova, B., Zineb, T. B., Sittner, P., 2012. Thermomechanical model for niti-based shape memory alloys including r-phase and material anisotropy under multiaxial loadings. International Journal of Plasticity 39 (0), 132 - 151.

Tanaka, K., Kobayashi, S., Sato, Y., 1986. Thermomechanics of transformation pseudoelasticity and shape memory effect in alloys. International Journal of Plasticity 2, 59-72.

Thoma, P. E., Boehm, J. J., 1999. Effect of composition on the amount of second phase and transformation temperatures of $N i_{x} T i_{90-x} H f_{10}$ shape memory alloys. Materials Science and Engineering A 273-275, 385-389.

Wu, S., Wayman, C., 1987. Martensitic transformations and the shape-memory effect in $T i_{50} N i_{10} A u_{40}$ and $T i_{50} A u_{50}$ alloys. Metallography 20 (3), 359-376.

Zaki, W., Zamfir, S., Moumni, Z., 2010. An extension of the zm model for shape memory alloys accounting for plastic deformation. Mechanics of Materials 42 (3), 266 - 274. 